\title{
Population Exposure to Fine Particles
}

METHODOLOGY AND RESULTS FOR OECD AND G20 COUNTRIES 


\section{OECD GREEN GROWTH PAPERS}

The OECD Green Growth Strategy, launched in May 2011, provides concrete recommendations and measurement tools to support countries' efforts to achieve economic growth and development, while at the same time ensuring that natural assets continue to provide the ecosystem services on which our well-being relies. The strategy proposes a flexible policy framework that can be tailored to different country circumstances and stages of development.

This paper has been authorised for publication by Mr. Simon Upton, Director, Environment Directorate. OECD Green Growth Papers should not be reported as representing the official views of the OECD or of its member countries. The opinions expressed and arguments employed are those of the author(s). The statistical data for Israel are supplied by and under the responsibility of the relevant Israeli authorities. The use of such data by the OECD is without prejudice to the status of the Golan Heights, East Jerusalem and Israeli settlements in the West Bank under the terms of international law. It should be noted that Latvia was not an OECD member at the time of preparation of this publication. Accordingly, Latvia does not appear in the list of OECD Members and is not included in the zone aggregates. This document and any map included herein are without prejudice to the status of or sovereignty over any territory, to the

delimitation of international frontiers and boundaries and to the name of any territory, city or area.

OECD Green Growth Papers aim to describe preliminary results or research in progress by the author(s) and are published to stimulate discussion on specific topics and obtain feedback from interested audiences.

They complement the OECD Green Growth Studies series, which aims to provide in-depth reviews of the green growth issues faced by different sectors.

Comments on Green Growth Papers are welcomed, and may be sent to:

OECD Green Growth Unit, 2, rue André Pascal, 75775 PARIS CEDEX 16, France

or by email to greengrowth@oecd.org.

OECD Green Growth Papers are published on:

www.oecd.org/greengrowth

Please cite this paper as:

Mackie A., Haščič I. and Cárdenas Rodríguez M. (2016), "Population Exposure to Fine Particles: Methodology and Results for OECD and G20 Countries", OECD Green Growth Papers, No. 2016/02, OECD Publishing, Paris.

\section{(C) OECD (2016)}

You can copy, download or print OECD content for your own use, and you can include excerpts from OECD publications, databases and multimedia products in your own documents, presentations, blogs, websites and teaching materials, provided that suitable acknowledgment of OECD as source and copyright owner is given. All requests for commercial use and translation rights should be submitted to rights@oecd.org. 


\begin{abstract}
This paper presents progress in elaborating an indicator of population exposure to $\mathrm{PM}_{2.5}$ with the objective to produce internationally harmonised indicators for all OECD and G20 countries. The paper takes stock of the various methodological options, including those based on data from ground-based monitoring, remote sensing, and a hybrid approach. A calculation methodology is described and examples of the indicator are presented for all OECD and G20 countries for the 1990-2013 time period. Possible next steps are identified with the aim of updating the indicator on a regular basis.
\end{abstract}

JEL classification: I18, O18, Q53, R11

Keywords: ambient air pollution, outdoor air pollution, remote sensing, ground monitoring, human exposure, health

\title{
RÉSUMÉ
}

Ce document présente l'état d'avancement des travaux de développement d'un indicateur de l'exposition de la population aux $\mathrm{PM}_{2.5}$ dont l'objectif est de produire des indicateurs harmonisés au plan international pour les pays de l'OCDE et du G20. Il fait le bilan des différentes options méthodologiques, notamment de celles qui s'appuient sur des données de surveillance au sol, sur des données de télédétection, et sur une approche hybride. Une méthode de calcul est décrite et des exemples sont présentés pour tous les pays de l'OCDE et du G20 pour la période 1990-2013. Le document expose les étapes suivantes envisagées pour assurer une mise à jour régulière de l'indicateur.

Classification JEL : I18, O18, Q53, R11

Mots clés : pollution de l'air ambiant, pollution de l'air extérieur, télédétection, surveillance au sol, l'exposition humaine, santé

\section{ACKNOWLEDGMENTS}

This paper was prepared by Alexander Mackie, Ivan Haščič and Miguel Cárdenas Rodríguez, under the supervision of Nathalie Girouard, head of Environmental Performance and Information Division of the OECD Environment Directorate. We wish to thank Michael Brauer (University of British Columbia, and the GBD team) for kindly providing data and guidance, and Jay Turner (Washington University in St. Louis), Bo Andrée and Eric Koomen (Free University of Amsterdam) for helpful advice. A previous version of this paper benefited from the comments of OECD colleagues including Nils Axel Braathen, Monica Brezzi, Myriam Linster, Paul O'Brien, Walid Oueslati, Pierre-Alain Pionnier, Valentine Rinner and Paul Schreyer. Jennifer Humbert and Jacqueline Maher provided editorial assistance.

The paper was reviewed by the OECD Environmental Policy Committee and its Working Party on Environmental Information. It also benefited from the comments received from country Delegates to the Working Party No. 1 on Macro-Economic and Structural Policy Analysis of the Economic Policy Committee (EPC) and the Committee on Statistics and Statistical Policy (CSSP). 


\section{FOREWORD}

The OECD Working Party on Environmental Information (WPEI) requested the Secretariat to further elaborate the OECD green growth headline indicators, proposed by the Reflection Group back in 2012. Population exposure to $\mathrm{PM}_{2.5}$ has been proposed for inclusion in the set of headline indicators. ${ }^{1}$ It measures exposure of human population to outdoor concentrations of particulate matter less than 2.5 micrometres in diameter $\left(\mathrm{PM}_{2.5}\right)$.

\section{OECD Green Growth headline indicators}

\begin{tabular}{|c|c|}
\hline \multicolumn{2}{|c|}{ Environmental and resource productivity } \\
\hline Carbon productivity & 1. $\mathrm{CO}_{2}$ productivity \\
\hline Resource productivity & 2. Non-energy material productivity \\
\hline Multifactor productivity & 3. Multifactor productivity including environmental services \\
\hline \multicolumn{2}{|r|}{ The natural asset base } \\
\hline Renewable and non-renewable stocks & 4. Natural resource index \\
\hline Biodiversity and ecosystems & 5. Changes in land use and cover \\
\hline \multicolumn{2}{|c|}{ Environmental quality of life } \\
\hline Environmental health and risks & 6. Air pollution (population exposure to PM 2.5) \\
\hline \multicolumn{2}{|c|}{ Economic opportunities and policy responses } \\
\hline $\begin{array}{l}\text { Technology and innovation, environmental goods } \\
\text { and services, prices and transfers, etc. }\end{array}$ & Placeholder - no indicator specified \\
\hline
\end{tabular}

Source: OECD (2014a), Green Growth Indicators.

The Delegates requested the Secretariat to examine a range of options and develop concrete proposals for the indicator. Building on the earlier work carried out by the OECD Working Party on Territorial Indicators, and drawing on a comprehensive review of data availability (see Turner, 2016), this paper presents the results of the recent work.

\footnotetext{
${ }^{1}$ The green growth (GG) headline indicators is a small set of indicators selected to track central elements of GG and to facilitate communication with policy makers, the media and citizens (see ENV/EPOC/WPEI(2012)2). The set has been proposed following the decisions of three OECD bodies - the Committee on Statistics and Statistical Policy (CSSP), the Working Party on Environmental Information (WPEI) of the Environmental Policy Committee (EPOC), and Working Party 1 of the Economic Policy Committee (EPC).
} 


\section{TABLE OF CONTENTS}

ABSTRACT

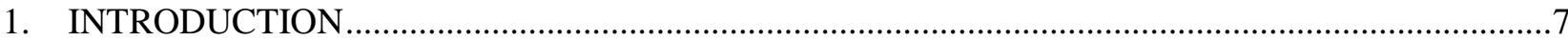

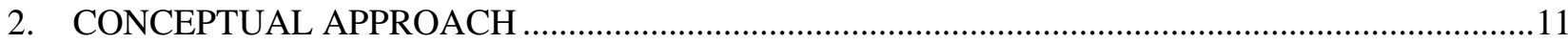

2.1. Exposure as an indicator of potential human health impacts of pollution ......................................11

2.2. Alternative indicator methodologies ............................................................................................11

2.2.1. Indicators based on air quality monitoring systems (ground measurements).......................11

2.2.2. Indicators based on global satellite observations (remote sensing) .......................................13

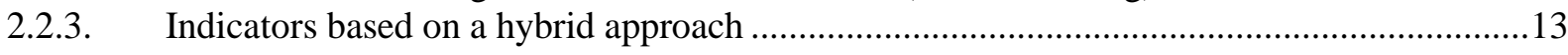

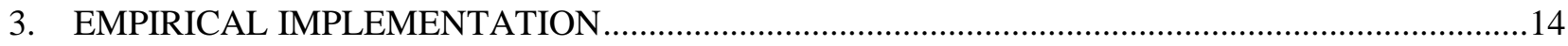

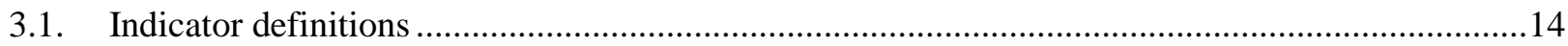

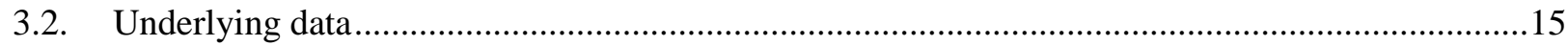

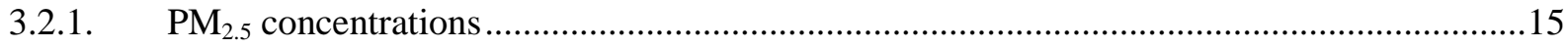

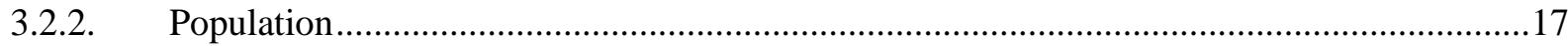

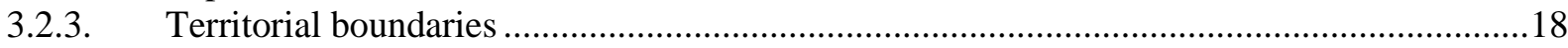

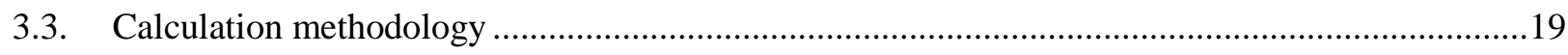

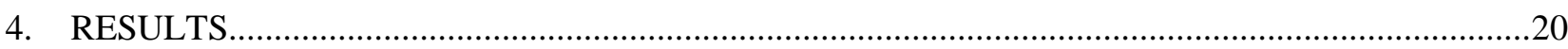

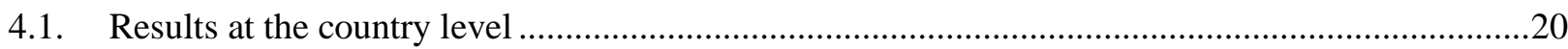

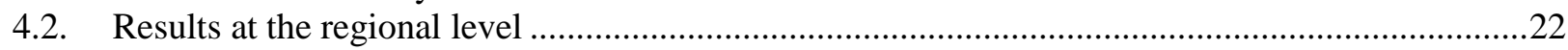

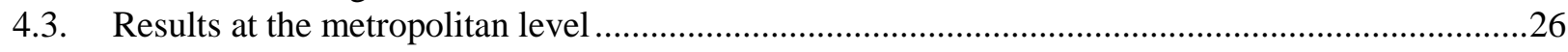

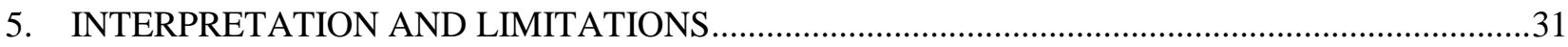

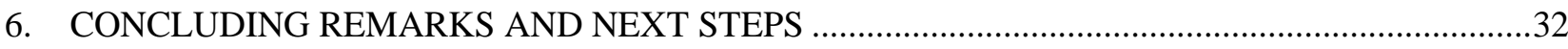

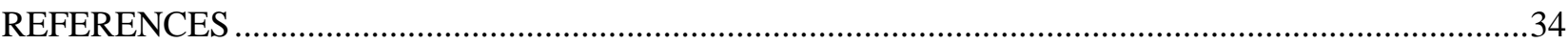




\section{Figures}

Figure 1. Mean population exposure to PM2.5

Figure 2. Percentage of population exposed to high and severe pollution by PM2.5 ….........................10

Figure 3. Estimated 2013 annual average PM2.5 concentrations from the GBD assessment modelling ..16

Figure 4. Gridded Population of the World (v4): population count estimates 2010, from NASA's

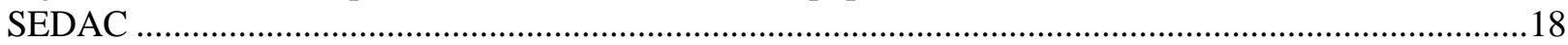

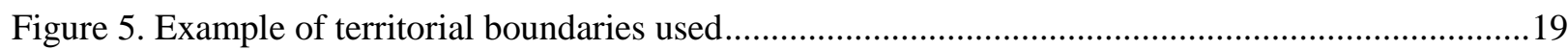

Figure 6. Population exposure to fine particles, TL1 country level (2013) ...........................................21

Figure 7. Population exposure to fine particles, TL1 country level (2013) ..........................................22

Figure 8. Mean exposure to $\mathrm{PM}_{2.5}$ in macro-regions (2013) ................................................................23

Figure 9. Mean exposure to $\mathrm{PM}_{2.5}$ in macro-regions (\% change 1990-2013) ............................................23

Figure 10. Mean exposure to $\mathrm{PM}_{2.5}$ in macro-regions in Europe (2013) ................................................24

Figure 11. Mean exposure to $\mathrm{PM}_{2.5}$ in macro-regions in Asia (2013) ..................................................24

Figure 12. Mean exposure to $\mathrm{PM}_{2.5}$ in macro-regions in Europe (\% change 1990-2013) ........................25

Figure 13. Mean exposure to $\mathrm{PM}_{2.5}$ in macro-regions in Asia (\% change 1990-2013) .............................25

Figure 14. Mean exposure to PM2.5 in metropolitan areas (2013) ....................................................26

Figure 15. Mean exposure to $\mathrm{PM}_{2.5}$ in selected metropolitan areas of Asia and America (2013) .............27

Figure 16. Mean exposure to $\mathrm{PM}_{2.5}$ in selected metropolitan areas of Asia and America (\% change 1990-

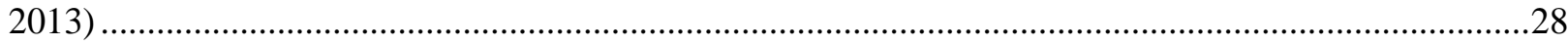

Figure 17. Mean exposure to $\mathrm{PM}_{2.5}$ in selected metropolitan areas in Europe (2013).............................29

Figure 18. Mean exposure to $\mathrm{PM}_{2.5}$ in selected metropolitan areas in Europe (\% change 1990-2013).....30

Figure 19. Population coverage of $\mathrm{PM}_{2.5}$ concentration data, 2013........................................................32

\section{Boxes}

Box 1. WHO Air Quality Guidelines and Interim Targets .15 
Air pollution is considered one of the most pressing environmental and health issues across OECD countries and beyond. Fine particulate matter $\left(\mathrm{PM}_{2.5}\right)$ can be inhaled and cause serious health problems including both respiratory and cardiovascular disease. In 2013, a WHO assessment concluded that exposure to outdoor particulate matter is carcinogenic to humans.

Population exposure to $\mathrm{PM}_{2.5}$, which has potentially the most significant adverse effects on health compared to other pollutants, has been identified as a Green Growth headline indicator. This indicator is already used in OECD work. Indicators of population exposure to air pollution are included in the Core Set of Environmental Indicators under the issue "environmental dimensions of quality of life", and were identified as one of the OECD's Key Environmental Indicators endorsed by Environment Ministers in 2001. Such indicators are included in the OECD Regional Database, OECD Regional Well-Being Database, and OECD Metropolitan Database and are an input to the OECD work on measuring the progress of societies (OECD Better Life Initiative; How's life? 2015; How's Life in Your Region? 2014).

The OECD has produced several air quality indicators in the past (e.g. information on air pollutant concentrations has been collected as part of the regular data collection from countries through the State of the Environment questionnaire and from other international sources; other examples include average concentrations of $\mathrm{PM}_{10}, \mathrm{CO}$ and $\mathrm{NO}_{2}$ for European cities using data from ground-based monitoring (Cárdenas et al., 2015), and average concentrations of $\mathrm{NO}_{2}$ (OECD, 2013) and $\mathrm{PM}_{2.5}$ (OECD, 2011) using remotely sensed data). A subset of these indicators focused specifically on exposure, including:

- Population exposure to $\mathrm{PM}_{10}$ - using data from ground-level monitoring for year 2010 , for 23 European countries, expressed as the percentage of population exposed to annual average $\mathrm{PM}_{10}$ greater than (and less than) $20 \mu \mathrm{g} / \mathrm{m} 3$ (OECD, 2013).

- Population exposure to $\mathrm{NO}_{2}$ - using remotely sensed data for 2011-12, for OECD and 5 BRICS countries in terms of both national- and sub-national averages (OECD, 2013).

- Population exposure to $\mathrm{PM}_{2.5}$ - using remotely sensed data for 2001-2006 (van Donkelaar et al., 2010) for OECD and 5 BRICS countries (OECD, 2011).

- Population exposure to $\mathrm{PM}_{2.5}$ - using remotely sensed data for 2002-12 (van Donkelaar et al., 2015) for OECD and 5 BRICS countries (OECD, 2015; Brezzi and Sanchez-Serra, 2014).

Up-to-date and internationally harmonised indicators on the environmental dimension of quality of life provide an essential underpinning for country reviews. Several recent Environmental Performance Reviews as well as Economic Surveys have discussed air pollution impacts, and there is a growing interest by countries to deepen analysis of these issues. ${ }^{2}$ There is equally an interest to link such analysis with Going for Growth publications to better integrate the environmental dimension of well-being and the side effects of growth-enhancing policy objectives into more holistic policy advice for member countries.

\footnotetext{
${ }^{2}$ For example, the Economic Surveys of China (2015; 2013), Korea (2014), Latvia (2015), Poland (2014), Belgium (2015), Slovenia (2013), France (2015), the European Union (2014) and Canada (2014) all discussed air pollution issues.
} 
However, a lack of commensurable indicators across OECD countries and beyond is a major obstacle to such efforts.

The exposure to air pollution has been a focus of on-going work by the Regional Development Policy Committee (RDPC) and its Working Party on Territorial Indicators (WPTI) to provide internationally comparable measures of population exposure to air pollution in regions, cities and metropolitan areas (see e.g. OECD, 2013). The same indicator has been used to measure outcomes in the environmental dimension of the OECD Well-Being work both at the national and subnational levels (see e.g. How's Life 2015; How's Life in Your Region 2014). More recently, the Environmental Policy Committee (EPOC) launched the work on Spatial Planning Instruments and the Environment (SPINE) which has been reflected in the work programmes of the Working Party on Integrating Environmental and Economic Policies (WPIEEP) and the Joint Meetings of Tax and Environment Experts (JMTEE), with WPEI's role to provide a possible information basis for such policy analyses. Related work is conducted by the Economics Department and the Centre for Tax Policy and Administration, with a focus on policy instruments (see e.g. Brandt, 2014).

This paper reports on a comprehensive assessment of the available approaches to measure exposure to fine particles (the GG headline indicator). The following criteria were considered:

- Achieve the broadest possible geographic coverage of OECD and G20 countries, and possibly beyond. $^{3}$

- An essential objective is achieving coherence across countries;

- Availability of time series to allow observing trends over an extended period of time which is particularly important for (slow-moving) environmental variables;

- Availability of future updates at regular intervals (timeliness);

- Whenever possible, provide a greater degree of granularity in addition to the national level aggregates. This is important for country reviews where availability of such information would allow for a more comprehensive and nuanced assessment of countries' performance and better targeted policy advice. Moreover, the proposed indicators and the underlying data must be suitable for use across a range of applied policy work, including in the OECD's work on territorial indicators and regional analysis, work on spatial planning instruments and the environment, and work on ecosystem services in agriculture. ${ }^{4}$

- Ensure that production and maintenance of the indicators in the future can be done at the lowest possible cost (i.e. insofar possible rely on freely available data, use open-source software, and automate routine updates).

Against this background, the Secretariat has undertaken the following developmental work:

- A comprehensive review of relevant data sources that could underpin the production of the indicator: The review has been directed at data sources for OECD and G20 countries (46 countries) $)^{5}$ assessing the measurement method, representativeness, reliability, periodicity, timeliness, geographic coverage, pollutants measured and accessibility of data (Turner, 2016).

\footnotetext{
3 There is a growing demand within the OECD to provide information to support the Organisation's regional initiatives, including those in MENA countries, Southeast Europe, the EECCA region, as well as Southeast Asia and Latin America. This requires using data sources with a near-global coverage.

${ }^{4}$ This means that they need to be generated using geospatial data so that, in addition to country-level indicators, the corresponding indicators can also be generated at the appropriate regional and local levels.

${ }^{5}$ Including 35 OECD members, 3 accession candidates and the 8 remaining G20 countries.
} 
- A comprehensive review of metrics and methodologies that could usefully support the construction of harmonised indicators, focusing on ways how the key differences across countries in measured attributes can be best addressed.

- Implementation of a production process that is transparent and replicable over time and at the least cost.

\section{Main findings}

This paper proposes a practically feasible and cost-effective solution for producing the indicator on a regular basis at the national and sub-national levels for all OECD and G20 countries, and possibly beyond.

The preferred approach to produce indicators of exposure to outdoor air pollution is a hybrid one - combining satellite-based estimates and ground-based measurements. This methodological choice allows the key shortcomings of ground-based data to be overcome (i.e. limited geographic coverage and lack of comparability across ground-based networks) and the accuracy of remote sensing estimates to be improved. The proposed approach applies a standardised methodology to achieve a wide geographical coverage, with estimates available also in countries and regions without extensive ground monitoring, such as in rural areas. However, even in locations with high ground monitor density, the satellite retrievals provide additional information because no monitoring network fully captures the entire population. This methodology will allow updating the indicator at regular intervals in the future (it is expected that annual updates will be possible).

This paper presents three indicators of exposure to outdoor air pollution:

- Mean population exposure to outdoor $P M_{2.5}$ proposed as a Green Growth headline indicator, defined as population-weighted average annual concentration of $\mathrm{PM}_{2.5}$;

- Percentage of population exposed to high levels of $P M_{2.5}$, defined as the proportion of people living in areas with annual concentrations exceeding the WHO Air Quality Guideline (AQG) value of 10 micrograms per cubic meter; and

- Percentage of population exposed to severe pollution by $P M_{2.5}$, defined as the proportion of people living in areas with concentrations exceeding the WHO Interim Target (IT) values of, respectively, 15, 25 and 35 micrograms per cubic meter, proposed to serve as complementary indicators.

The indicators are available for all OECD and G20 countries (46 countries) for the 1990-2013 time period, at the national and sub-national levels. The results (Figure 1) suggest that in OECD countries the mean population exposure to $\mathrm{PM}_{2.5}$ has decreased by 33\%, on average, during the last two decades. However, the exposure level in 2013 still was above the recommended guidelines of the World Health Organisation. An opposite trend has been observed in BRIICS countries, where the population exposure increased even further from already high levels in 1990 to severe levels in 2013 (an increase by 39\%, on average). 
Figure 1. Mean population exposure to PM2.5

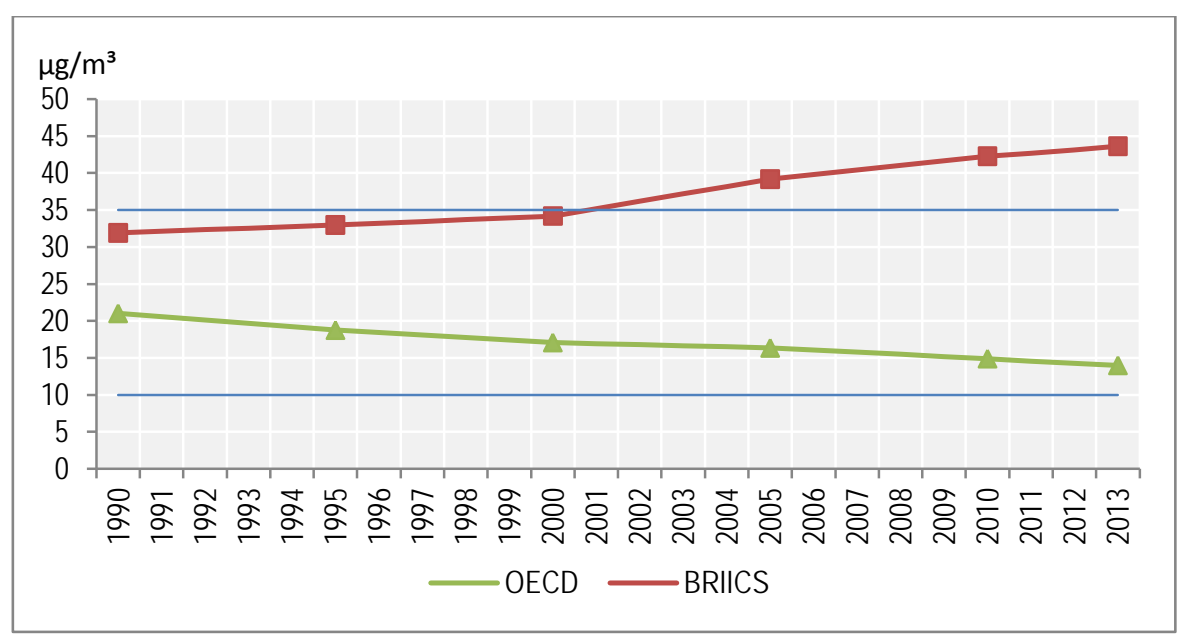

In 1990, almost $7 \%$ of the population in the OECD was exposed to severe pollution, and while this share has gone down substantially, in 2013 still about 2\% of OECD's population lived in areas with concentrations of $\mathrm{PM}_{2.5}$ higher than 35 micrograms per cubic metre - the highest WHO interim target level (Figure 2). In BRIICS countries, the percentage of population exposed to such severe pollution by $\mathrm{PM}_{2.5}$ has gone up dramatically from 39\% in 1990 to almost 59\% in 2013, causing serious threats to human health.

Figure 2. Percentage of population exposed to high and severe pollution by PM2.5

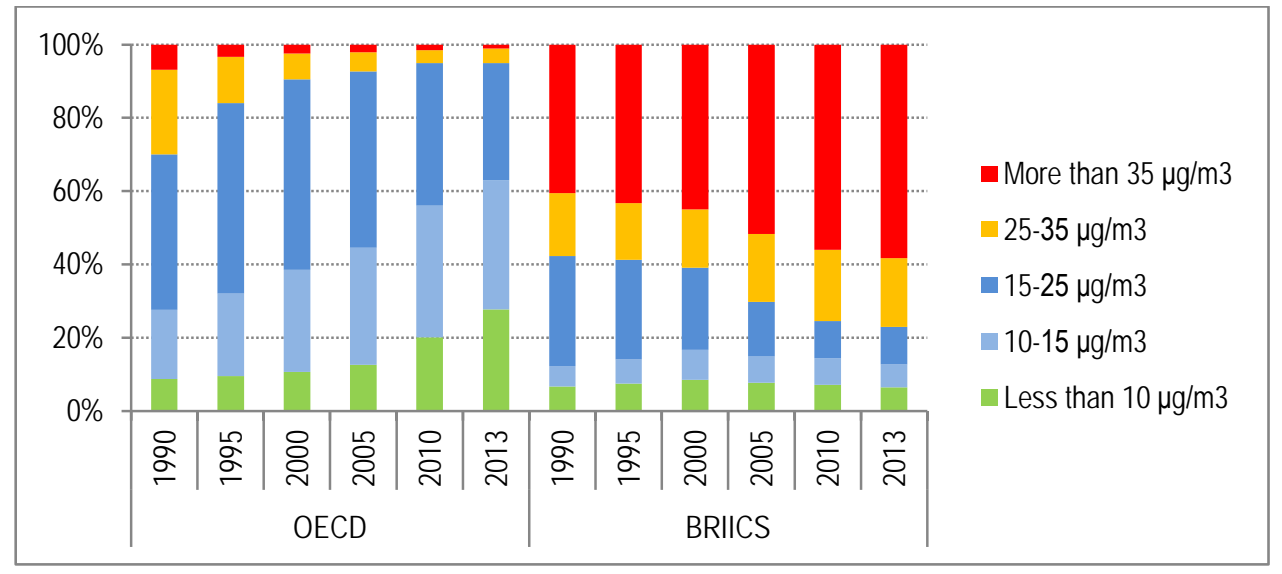

The indicators will be generated at four spatial levels including at the national (country) and subnational levels (macro region, micro region, metropolitan area). Preference will be given to the OECD Territorial Classification whenever available, and for the remaining countries it will be complemented with alternatives such as the FAO Global Administrative Unit Layers.

The remainder of this paper is organised as follows: Section 2 examines the range of possible indicator definitions and available data sources. Section 3 discusses the proposed indicator - its definition, the underlying data and the calculation methodology. Section 4 presents examples of the indicators for OECD and G20 countries. Section 5 provides guidance on the interpretation of the indicators and their caveats. 


\section{CONCEPTUAL APPROACH}

\subsection{Exposure as an indicator of potential human health impacts of pollution}

Outdoor air pollution is responsible for more than 3 million deaths across the world every year, and many more people are impacted by ill health, with significant costs for the society. In the OECD area, China and India, the damage has been estimated at USD 3.5 trillion per year in terms of the value of lives lost and ill health (OECD, 2014).

Information on exposure to harmful air pollutants is a key element in the design of effective policy responses. However, measuring population exposure to air pollution is not straightforward. Average values of outdoor concentrations are only appropriate in the vicinity of the measurement location. This is because negative impacts of environmental quality are spatially heterogeneous (a given concentration might have high or low impacts depending on the probability of exposure). For this reason, rather than average concentrations, the indicators proposed here measure exposure (i.e. population-weighted concentrations, such as those shown in Figures 1 and 2 above).

A meaningful indicator of air pollution must be correlated with potential negative impacts on human health. While exposure indicators at the local level are straightforward in computation and interpretation, at a more aggregate level (large metropolitan area, region, country), providing a meaningful measure of air pollution exposure is more challenging given the spatial heterogeneity of pollution concentration. Thus, an ideal indicator would aggregate information about pollution in high-impact areas as opposed to pollution that is confined to areas with low potential impacts. This objective can be achieved by overlaying geo-referenced information on population settlements and on pollution measurements. Aggregate measures would then account for the population exposed to each level of pollution. This would allow 'hotspots' to be identified in terms of levels of exposure and changes over time.

A range of pollutants posing health concerns for the exposed population are continuously monitored by national networks. The WHO has singled-out $\mathrm{PM}_{2.5}$ and $\mathrm{O}_{3}$ to be of primary concern. This is because chronic and acute exposures to $\mathrm{PM}_{2.5}$ have been identified as the most robust indicator of adverse (mortality) impacts (Brauer et al., 2016), having its most severe effects on children and elderly people. In addition, ozone exposure concern is primarily motivated by its adverse impact on respiratory health. Patterns of ozone concentrations are often distinct from those of PM, as are the relative importance of ozone precursors. Thus, additional to $\mathrm{PM}_{2.5}$, ozone exposure indicators could provide a more complete picture in regards to human exposure to pollution. There is also increasing evidence that $\mathrm{NO}_{2}$ exposure represents a separate threat to human health although its precise effects are not yet fully understood.

\subsection{Alternative indicator methodologies}

\subsubsection{Indicators based on air quality monitoring systems (ground measurements)}

Air quality measures from ground-based monitoring stations can be used for the calculation of population exposure indicators. There are two ways to assign concentration estimates to locations away from the monitoring site, namely spatial interpolation and buffer zones.

Spatial interpolation consists in weighting the monitor site concentration data based on distance to the location of interest. More weight is given to monitors close to the point of interest while monitors farther away have less influence. Spatial interpolation has advantages of complete spatial coverage (except perhaps at the extreme edges of the domain) and provides for spatial gradients in concentration which is 
indeed observed. However, there are challenges in selecting appropriate weighting functions for interpolating air pollution data, especially over large spatial scales. For example, for pollutants with significant urban excess, a relatively high density of rural monitors is needed to capture steep gradients in concentrations in the areas between cities.

Buffers are spatial zones drawn around each monitor, such as circles of a given radius. The buffer zone approach then assigns the same concentration value to all locations in such circle. This approach has the advantage of not seeking to inform concentrations at large distances from monitors where the representativeness is questionable. However, selection of the buffer zone size is to a large extent subjective. It largely depends on the pollutant and spatial scale of emission sources that impact the monitoring location as well as the specific metadata of the measurement site (e.g. geophysical information of the site). Another clear disadvantage of the buffer zone approach is that there can be large portions of the population with no exposure estimate assigned. ${ }^{6}$

The resulting spatially resolved concentration fields are then overlaid with high spatial resolution population density data to construct the distribution of population exposures to the pollutant. The key advantage of population exposure indicators from ground monitoring is the higher level of detail in terms of spatial resolution, periodicity (hourly measurements) and accuracy (in terms of on-site measurement of the pollution levels). On the other hand, the data can be highly heterogeneous due to the limited geographical coverage, its representativeness within and across countries, as well as measurement methodology. ${ }^{7}$ The lack of extensive air quality monitoring networks is still a challenge in many OECD countries, and even more so in other countries despite some of the recent efforts to strengthen groundbased monitoring and data sharing.

Finally, to address some of the shortcomings of ground-based measurements, econometric techniques have been applied to predict concentrations in places without measuring stations. These approaches include the model-based estimation of pollution concentration based on socio-economic patterns. ${ }^{8}$ They offer a good alternative to overcome the problems of ground-monitoring data but depend on the availability of external data. ${ }^{9}$

\footnotetext{
${ }^{6}$ Considerable effort is needed to develop justifiable buffer sizes. The variability across overlapping buffers in areas with a high density of monitors provides an indication of the estimation error and buffer sizes might be chosen to reduce such variability. For a detailed discussion, see Turner (2016).

${ }^{7}$ This makes pollution measurements from ground monitoring subject to comparability issues (see Turner, 2016).

${ }^{8}$ For example, the World Bank produced measures of the country-level cost of health damages from exposure to outdoor $\mathrm{PM}_{10}$ using the Global Model of Ambient Particulates (GMAPS) (Cropper and Khanna, 2014). The model was used to generate out-of-sample predictions of average annual $\mathrm{PM}_{10}$ concentration in over 3000 cities worldwide as a function of country-level per capita energy consumption by fuel, population density, per capita GDP, and city-level population, population density, GDP per $\mathrm{km}^{2}$ and local climate characteristics.

${ }^{9}$ The robustness of results will depend on the availability of data on the determinants of pollution, which can vary significantly across and within countries and regions.
} 


\subsubsection{Indicators based on global satellite observations (remote sensing)}

Recent advances in remote sensing have provided global observations for a wide range of air pollutants, including $\mathrm{PM}_{2.5}$, tropospheric $\mathrm{O}_{3}, \mathrm{NO}_{2}, \mathrm{CO}, \mathrm{HCHO}$ and $\mathrm{SO}_{2}$. Satellite retrievals are done passively, measuring the solar backscatter or thermal infrared emissions. The remote sensing instruments do not directly measure the atmospheric composition; rather they actively transmit energy downward and measure the backscatter. Retrievals are conducted by calculating the atmospheric composition that best reproduces the observed radiation. Such retrievals often require external information on geophysical fields (Martin, 2008).

Remotely sensed tropospheric measurements are then used to derive surface concentration of pollutants. This inverse modelling approach consists of applying scaling factors from a chemical transport model to tropospheric measurements in order to calculate the ground-level concentrations that would reproduce the observations. The quality and accuracy of this approach has been continuously improving with the availability of higher resolution optical sensors and refinements of the chemical transport models (van Donkelaar et al., 2010, 2015; Turner, 2016).

However, one limitation of this approach is the narrow coverage of pollutants measured relative to those from ground-based stations. Moreover, the measurements represent an average over a long time period (typically a year) which constrains the range of indicators that can be created.

1. On the other hand, this approach offers a global geographic coverage and standardised measurement. This allows the $\mathrm{PM}_{2.5}$ exposure indicators to be generated in manner that is commensurable across countries and with a broad geographic coverage (potentially any country worldwide).

\subsubsection{Indicators based on a hybrid approach}

Information from global remote sensing is increasingly used to evaluate and improve air quality measurements. This is the case of the Global Burden of Disease (GBD) approach, which combines satellite-based aerosol optical depth retrievals (AOD), chemical transport model (CTM), and ground-level monitoring data to generate global concentration fields with high spatial resolution (Brauer et al., 2016). This approach allows the parameters in the chemical transport model to be calibrated more accurately by comparing ground-level measurements and satellite retrievals. By measuring the discrepancies observed in areas with good ground-monitoring networks, the hybrid approach can produce more accurate pollutant concentration estimates in areas without in-situ measurements.

It is proposed that the $\mathrm{PM}_{2.5}$ concentration estimates from the hybrid approach are the best available estimates for the purposes of generating internationally harmonised indicators for all OECD and G20 countries, and at improved accuracy levels compared to previous work. The same underlying data have been used in the main Global Burden of Disease analysis ${ }^{10}$ as well as the recently updated World Bank's population-weighted country-level estimates. ${ }^{11}$ The proposed approach would be consistent with OECD's work on the cost of air pollution (OECD, 2014) which was based on GBD's estimates of human health impacts. (See Section 3 for a more detailed discussion of the hybrid approach.)

\footnotetext{
${ }^{10}$ Assessment of the disease burden, in terms of years of life lost and similar indicators, involves additional steps beyond the estimation of average pollutant concentrations, see http://ghdx.healthdata.org/

${ }^{11}$ http://wdi.worldbank.org/table/3.13 and http://data.worldbank.org/indicator/EN.ATM.PM25.MC.M3
} 


\section{EMPIRICAL IMPLEMENTATION}

\subsection{Indicator definitions}

The following three indicators are proposed: Mean exposure to outdoor $\boldsymbol{P M}_{2.5}$ calculated as the mean annual concentration of outdoor $\mathrm{PM}_{2.5}$ weighted by population residing in the relevant area (i.e. average exposure of the average resident). More formally:

$$
\text { Exposure }=\frac{\sum_{i}\left(P O P_{i} * P M 2.5_{i}\right)}{\sum_{i} P O P_{i}}
$$

where $i=1, \ldots, N$ refers to the grid cells belonging to the same spatial unit (country, region, metropolitan area), $P O P_{i}$ is the number of residents in a given grid cell, and $P M 2.5_{i}$ is the estimated mean annual concentration of $\mathrm{PM}_{2.5}$ in grid cell $i$. This definition is proposed for the Green Growth headline indicator. $^{12}$

Percentage of population exposed to high levels of $\mathrm{PM}_{2.5}$ (exceeding the WHO guideline) calculated as the number of residents in areas with mean annual concentrations exceeding the World Health Organization's (WHO) Air Quality Guideline (AQG) value (i.e., 10 micrograms per cubic meter, see WHO, 2006: pp.11) relative to total population in the studied area. The WHO-AQG value is the lower end of the range of mean annual concentrations over which adverse health effects due to $\mathrm{PM}_{2.5}$ exposure have been observed. Thus, this indicator allows the share of population exposed to high levels of pollution to be compared across different geographic regions:

$$
P C T_{-} \text {above } 10=\frac{\sum_{i} P O P_{i \mid P M 2.5>10 \mu g}}{\sum_{i} P O P_{i}} * 100
$$

where $P O P_{i \mid P M 2.5>10 \mu g}$ refers to the number of residents in grid cells where the AQG value of 10 micrograms per cubic meter is exceeded.

Percentage of population exposed to severe pollution by $P M_{2.5}$ (exceeding the WHO interim targets) calculated as the percentage of people living in areas with mean annual concentrations exceeding the WHO Interim Target (IT) values (i.e. 15, 25 and 35 micrograms per cubic meter, respectively) relative to total population:

$$
P C T_{-} \text {aboveIT }=\frac{\sum_{i} P O P_{i \mid P M 2.5>I T}}{\sum_{i} P O P_{i}} * 100
$$

where IT $\in\left\{15,25,35 \mu \mathrm{g} / \mathrm{m}^{3}\right\}$ refers to one of the three WHO Interim Target values, and $P O P_{i \mid P M 2.5>I T}$ refers to the number of residents in grid cells where the Interim Target (IT) value is exceeded. These four additional sub-indicators usefully complement the headline indicator.

"Mean exposure" is preferred over the "percentage of people exposed" as the headline indicator because it aggregates over an entire population and allows tracking even minor variations over time whereas the complementary "percentage of people exposed" indicators could hide such changes. For example, doubling of exposure from 2 to $4 \mu \mathrm{g} / \mathrm{m}^{3}$ for the lowest tier of exposed population would leave the "percentage of people exposed to levels above $10 \mu \mathrm{g} / \mathrm{m}^{3}$ ” unchanged.

\footnotetext{
${ }^{12}$ The corresponding (unweighted) mean concentration of $\mathrm{PM}_{2.5}$ can be calculated as $\frac{\sum_{1}^{N} P M 2.5_{i}}{N}$ which is not a reliable indicator of exposure over large geographic areas because it does not account for the heterogeneity of population exposures.
} 


\section{Box 1. WHO Air Quality Guidelines and Interim Targets}

WHO provides air quality guidelines based on scientific evidence and expert advice. Such guidelines were first produced in 1987 and later updated in 1997 and 2005. The current guidelines and interim targets for $\mathrm{PM}_{2.5}$ annual mean concentrations are shown below.

\begin{tabular}{|c|c|l|}
\hline & $\mathrm{PM}_{2.5}\left(\mu \mathrm{g} / \mathrm{m}^{3}\right)$ & \multicolumn{1}{|c|}{ Basis for the selected level } \\
\hline $\begin{array}{c}\text { Interim target-1 } \\
\text { (IT-1) }\end{array}$ & 35 & $\begin{array}{l}\text { These levels are associated with about a 15\% higher long-term } \\
\text { mortality risk relative to the AQG level. }\end{array}$ \\
\hline $\begin{array}{c}\text { Interim target-2 } \\
\text { (IT-2) }\end{array}$ & 25 & $\begin{array}{l}\text { In addition to other health benefits, these levels lower the risk of } \\
\text { premature mortality by approximately 6\% [2-11\%] relative to } \\
\text { the IT-1 level. }\end{array}$ \\
\hline $\begin{array}{c}\text { Interim target-3 } \\
\text { (IT-3) }\end{array}$ & 15 & $\begin{array}{l}\text { In addition to other health benefits, these levels reduce the } \\
\text { mortality risk by approximately 6\% [2-11\%] relative to the IT-2 } \\
\text { level. }\end{array}$ \\
\hline $\begin{array}{c}\text { Air quality } \\
\text { guideline (AQG) }\end{array}$ & 10 & $\begin{array}{l}\text { These are the lowest levels at which total, cardiopulmonary and } \\
\text { lung cancer mortality have been shown to increase with more } \\
\text { than 95\% confidence in response to long-term exposure to } \\
\text { PM }_{2.5}\end{array}$ \\
\hline
\end{tabular}

Source: WHO, 2006.

\subsection{Underlying data}

\subsection{1. $\quad P M_{2.5}$ concentrations}

This paper uses the calibrated gridded global annual mean $\mathrm{PM}_{2.5}$ concentration data from the GBD 2013 project for years 1990, 1995, 2000, 2005, 2010, 2011, 2012 and 2013 (Brauer et al., 2016). As discussed in Turner (2016), and updated here to reflect the developments for GBD 2013, the summarised methodology used to produce the gridded $\mathrm{PM}_{2.5}$ concentration data is the following:

i. $\quad$ Near-surface $\mathrm{PM}_{2.5}$ concentrations are estimated by combining satellite-derived Aerosol Optical Depth (AOD) retrievals informed by data from the MODIS ${ }^{13}$ (Moderate Resolution Imaging Spectroradiometer), MISR ${ }^{14}$ (Multi-angle Imaging Spectroradiometer), SeaWIFS ${ }^{15}$ (Sea-Viewing Wide Field-of-View Sensor) and CALIPSO ${ }^{16}$ (Cloud-Aerosol Lidar and Infrared Pathfinder Satellite Observations) satellite instruments from $1998-2012$ at $0.1^{\circ} \times 0.1^{\circ}$ resolution with the GEOS-Chem ${ }^{17}$ CTM simulations based on anthropogenic emissions from the Emissions Database for Global Atmospheric Research (EDGAR) ${ }^{18}$. The Chemical Transport Model (CTM) is used to both estimate ground-level concentrations of $\mathrm{PM}_{2.5}$ based on observed AOD retrievals and also to extend estimates back to 1990 using the ratio of emissions between 2005 and the respective year of interest;

\footnotetext{
${ }^{13}$ See http://modis.gsfc.nasa.gov/

${ }^{14}$ See www-misr.jpl.nasa.gov/

${ }^{15}$ See http://oceancolor.gsfc.nasa.gov/SeaWiFS/

${ }^{16}$ See www.nasa.gov/mission_pages/calipso/mission/

17 See http://acmg.seas.harvard.edu/geos/

${ }^{18}$ See http://edgar.jrc.ec.europa.eu/
} 
ii. Ground-level $\mathrm{PM}_{2.5}$ concentrations are also estimated using the European Commission's TM5FASST $^{19}$ CTM at $1^{\circ} \times 1^{\circ}$ resolution using emissions and meteorological data from sources including ECLIPSE ${ }^{20}$ (based on energy consumption and including international shipping) and $\mathrm{RCP}^{21}$ (for greenhouse gas concentrations) from the International Institute for Applied Systems Analysis (IIASA) and forest fire and savannah burning emissions data from the Global Fire Emissions Database ${ }^{22}$. Spatial variability at finer spatial resolution is estimated using population density as a proxy for emissions and the resulting model output is at $0.1^{\circ} \times 0.1^{\circ}$ resolution;

iii. Ground-level measurement data from over 3000 monitoring sites are used to calibrate the mean of the concentration estimates from steps (i) and (ii). ${ }^{23}{ }^{24} \mathrm{PM}_{2.5}$ concentration values are regressed on the modelled ground-level $\mathrm{PM}_{2.5}$ estimates. The resulting coefficients are then used to estimate ground-level $\mathrm{PM}_{2.5}$ at $0.1^{\circ} \times 0.1^{\circ}$ resolution across the globe;

iv. These steps are performed with annual averages.

Figure 3. Estimated 2013 annual average PM2.5 concentrations from the GBD assessment modelling

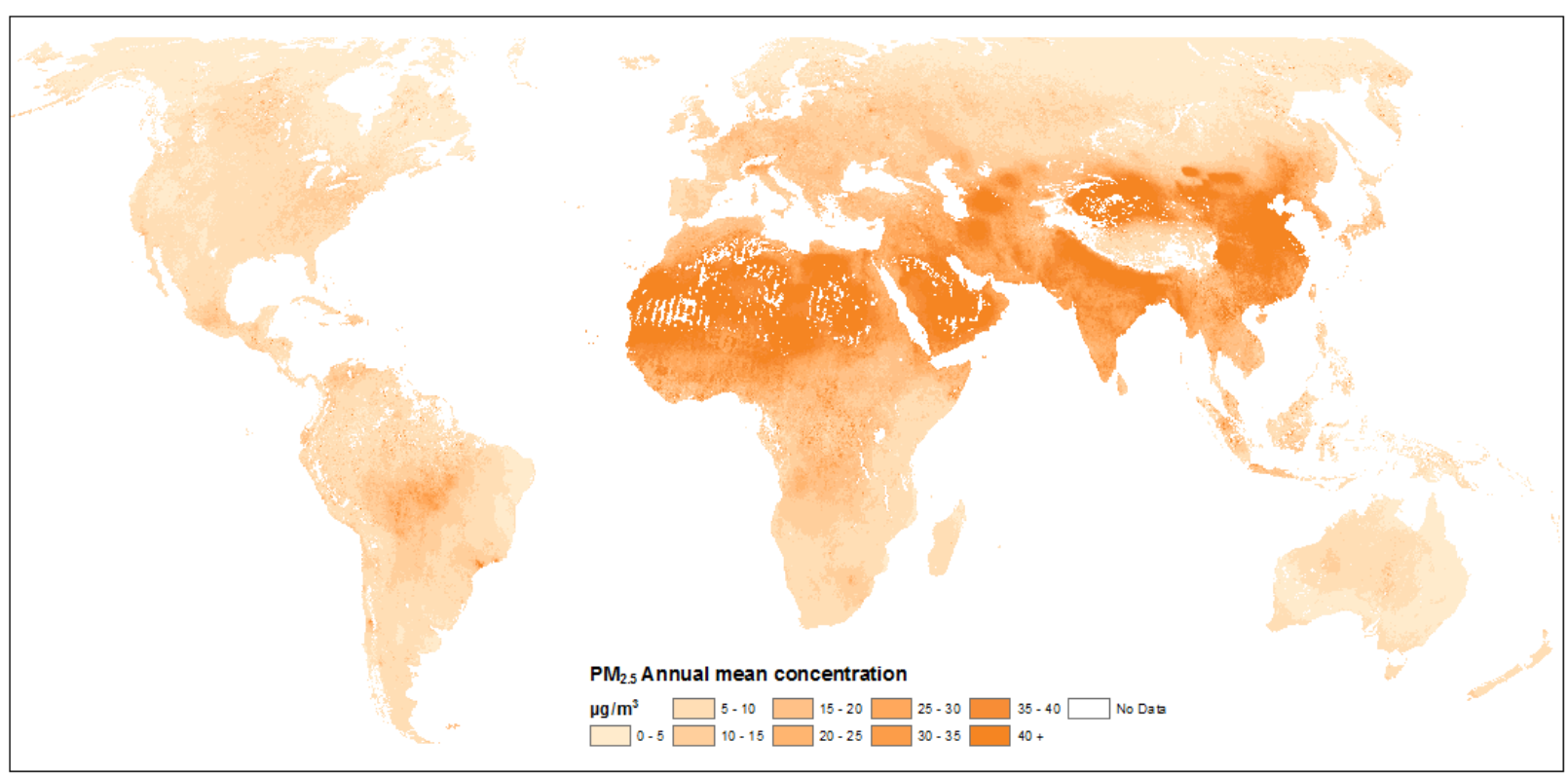

The $\mathrm{PM}_{2.5}$ concentration estimates reflect not only pollution from combustion sources but incorporate also the respirable fraction of crustal PM, or "dust” (Brauer, 2015). The latter likely plays an

\footnotetext{
${ }^{19}$ Core TM5-FASST paper is forthcoming.

${ }^{20}$ See http://eclipse.nilu.no/

${ }^{21}$ See http://tntcat.iiasa.ac.at/RcpDb/dsd?Action=htmlpage\&page=welcome

${ }^{22}$ See www.globalfiredata.org/

23 This places a much lower burden on the extensiveness of monitoring data compared to an indicator that is based exclusively on ground monitoring data (see Turner, 2016).

${ }^{24}$ In GBD 2015 the calibration using ground measurements will be further strengthened, compared to GBD 2013 used in this paper (Brauer, 2015).
} 
important role in explaining the concentration levels in countries of North Africa and the Middle East. However, in terms of exposure the available evidence does not support differential risk based on $\mathrm{PM}_{2.5}$ mixture composition (Brauer, 2015). This means that both the anthropogenic and non-anthropogenic sources of airborne fine particles are relevant from the human health perspective.

Moreover, distinguishing between exposure to man-made versus 'natural' sources of pollution is complicated due to a range of indirect human impacts (e.g. deforestation and agricultural practices leading to desertification) and is becoming increasingly blurred with rising climate change (e.g. changing precipitation patterns exacerbating desertification in some regions).

\subsubsection{Population}

The population data are available through SEDAC (Socioeconomic Data and Applications Center) at the NASA's Earth Observing System Data and Information System (EOSDIS). The Gridded Population of the World (GPWv4) in TIFF format for 2000, 2005, 2010 and 2015 are used. ${ }^{25}$ The underlying population data are collected from official national censuses, surveys or spatial data (if available) for over 12 million administrative units. These data are then allocated to each cell using a proportional allocation algorithm. The version 4 datasets are based on an extrapolation of sub-national growth rates obtained from census data collected circa 2010. The resolution is 30 arc seconds (approximately $1 \mathrm{~km}$ ). These gridded population files represent resident, or "night time", population and its accuracy and timeliness is dependent on those of the censuses and surveys. ${ }^{26}$

${ }^{25}$ See http://beta.sedac.ciesin.columbia.edu/data/collection/gpw-v4

${ }^{26}$ An alternative global population grid is LandScan which is generated as model-based time series for 2000-13, drawing on census information and other data that allow modelling the 24-hour population average (nighttime and daytime) and at $1 \mathrm{~km}$ resolution. The model-based nature also means that individual editions of the dataset are not directly comparable when the underlying model is refined, requiring the entire time series of LandScan to be purchased every time when the green growth indicator is updated. To avoid commitment to future costs, preference has been given to an alternative source of population data NASA's SEDAC - which is available for free. Moreover, the model-based nature of LandScan data might lead to endogeneity concerns in some applied analytical work.

For a comparison of these two alternatives, see also https://sedac.uservoice.com/knowledgebase/articles/41665what-are-the-differences-between-gpw-grump-and-la. 


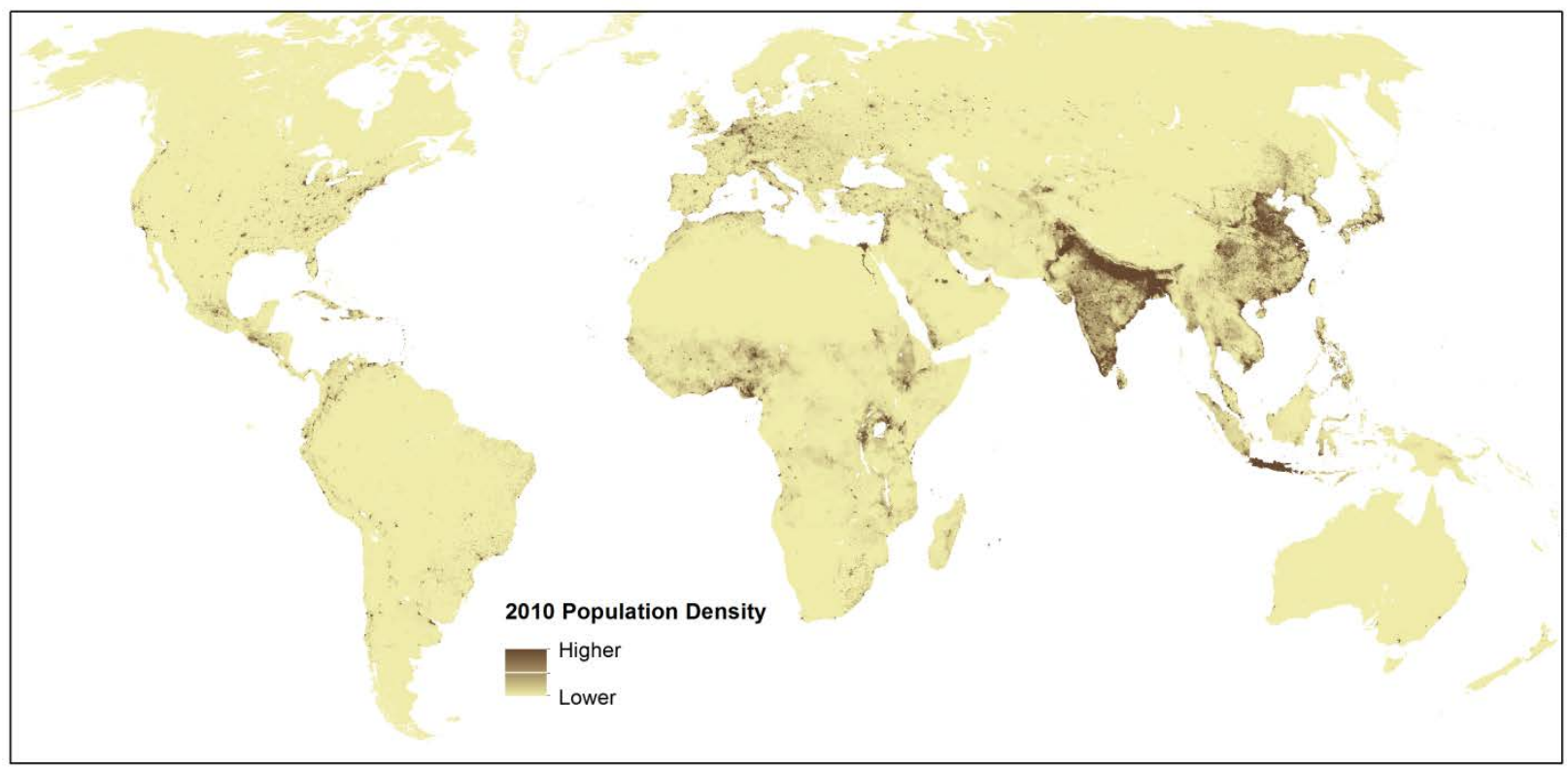

\subsubsection{Territorial boundaries}

The indicators can be produced at national and sub-national scales, including:

- country (territorial level 1, or TL1)

- macro-region (TL2) corresponding to the first tier of subnational governments and micro-region (TL3) corresponding to administrative or policy units, according to the OECD Territorial Classification $^{27,28}$. Boundaries of TL3 regions have not been made public by countries, thus the results in this paper cannot be applied to this level of geography. Countries will be asked to release this geography publicly and future revisions of the paper may include also TL3 regions. In the meantime, alternative boundary datasets will be used in cases when an OECD classification is not available, such as the FAO Global Administrative Unit Layers (GAUL) ${ }^{29}$. Such alternatives will be also applied for non-OECD countries.

- metropolitan area - based on the OECD-EU definition of functional urban areas (FUA). ${ }^{30}{ }^{31}$ This level of geography is particularly relevant in OECD countries where air pollution is predominantly an urban issue.

${ }^{27}$ For OECD countries, see www.oecd.org/gov/regional-policy/43428422.pdf; for BRIICS countries, see OECD (2011, Annex A.2).

${ }^{28}$ Note that, at the time of drafting this paper, TL2 official boundaries are not available for 7 of the 46 countries covered here (including Argentina, Colombia, Costa Rica, Indonesia, Latvia, Lithuania and Saudi Arabia) and TL3 boundaries are currently not available for any country.

${ }^{29}$ See $\underline{w w w . f a o . o r g / g e o n e t w o r k / s r v / e n / m e t a d a t a . s h o w ? i d=12691 ~}$

${ }^{30}$ www.oecd.org/gov/regional-policy/all.pdf.

${ }^{31}$ Note that, at the time of drafting this paper, FUA boundaries are not available for 17 of the 46 countries covered here (including Australia, Iceland, Israel, New Zealand, Turkey, Argentina, Brazil, China, Colombia, Costa Rica, India, Indonesia, Latvia, Lithuania, Russia, Saudi Arabia and South Africa). 
Examples of the TL1, TL2 and FUA boundaries for France are shown in Figure 5.

Figure 5. Example of territorial boundaries used
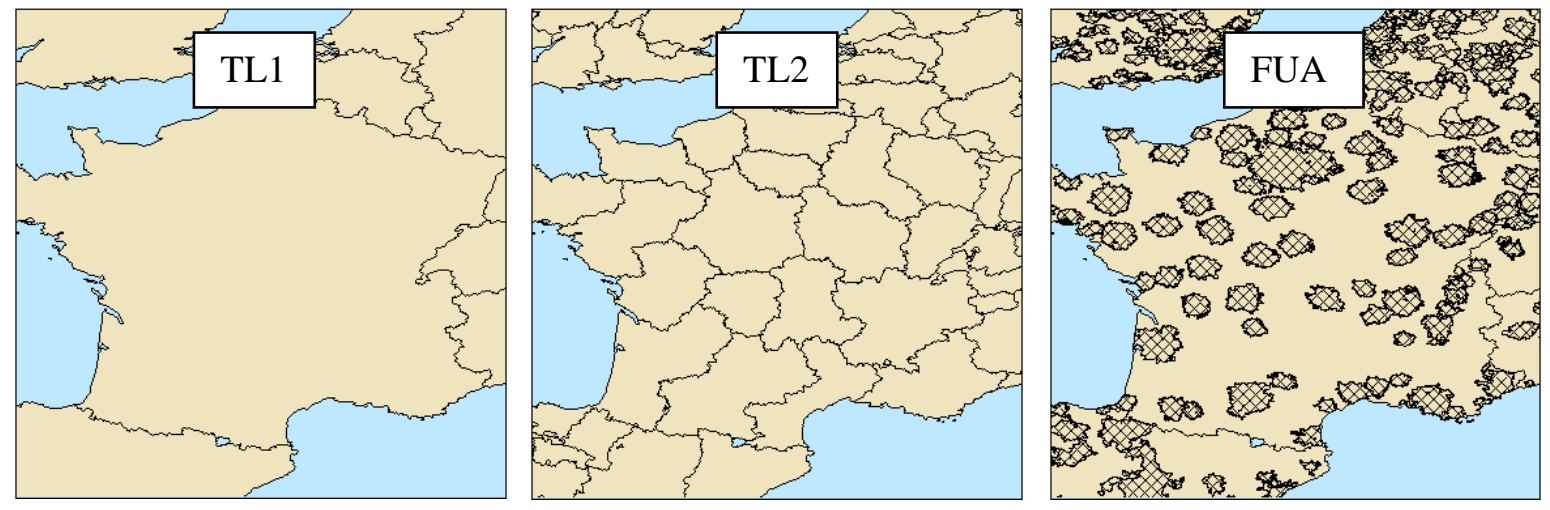

Development of the FUAs responds to the need for a commensurable definition of urban areas across countries. FUAs are metropolitan areas composed of municipalities (or the smallest geographic unit with available socio-economic data) selected using the LandScan global population grid and commuting data (travel from home to work) for cities with a minimum of 50000 inhabitants. All suburban municipalities with at least $15 \%$ of inhabitants working in the city are included. This definition of the boundary of a city takes better account of the economic function of cities when studying urban dynamics. The FUA definition also allows social, economic, environmental and governance indicators to be generated consistently for urban areas based on micro-level data (OECD, 2012).

\subsection{Calculation methodology}

SEDAC's v4 population files for years 2000, 2005, 2010 and 2015 were used. Population datasets for the years 1990 and 1995 were approximated by backward extrapolation of the cell-by-cell rate of change between 2000 and 2010 (using 0 as a floor). For the years 2011, 2012 and 2013 datasets were produced using linear interpolation on a cell-by-cell basis of the SEDAC estimates for 2010 and 2015.

There are minor inter-year variations in the coverage extent of the pollution concentration grids because of limitations in the remotely-sensed results from some highly reflective land areas which exhibit seasonality (e.g. snow cover). To produce the most comparable inter-year results, only cells that had uninterrupted data for every year in the input datasets were used in the analysis. ${ }^{32}$

For the construction of the mean exposure to $\boldsymbol{P M}_{2.5}$ (proposed headline indicator), an intermediate grid was produced for each study year where each cell is the product of the population cell value and the pollution cell value. Data for the same time period were used (i.e. the 1990 population data were used with the 1990 pollution data). This is performed at the resolution of the population dataset.

Zonal statistics were computed using the boundary datasets. The sum of the population cells within each zone and the sum of the intermediate grid (pollution* population) cells within each zone were computed. As shown in equation [1], the population-weighted mean is the sum of the intermediate grid divided by the sum of the population of the zone (country, region or FUA).

\footnotetext{
${ }^{32}$ We retain $94 \%$ of the total area and $97 \%$ of total population in the study area.
} 
To calculate the percentage of population exposed to high (severe) pollution by $\mathbf{P} \mathbf{M}_{2.5}$ (proposed complementary indicators), the pollution grids were reclassified into binary grids at 10, 15, 25 and 35 $\mu \mathrm{g} / \mathrm{m}^{3}$ concentrations at the resolution of the population dataset. Cells that exceeded the given threshold were given a value of 1 and cells that did not exceed the threshold were given a value of 0 . These binary grids were multiplied on cell-by-cell basis with the population data to create an intermediate grid representing the population exposed over the given threshold. The process of calculating zonal statistics was repeated using this grid. The sum of the cells in each zone gives the total population exposed over the threshold (the numerator in formulas [2] and [3]). In order to produce the percentages, the sums are then divided by the total of population in the area (the denominator in formulas [2] and [3]).

\section{RESULTS}

\subsection{Results at the country level}

Results for the proposed indicators are presented in Figure 6. In 2013, populations living in China, India, and Saudi Arabia were exposed, on average, to the highest levels of $\mathrm{PM}_{2.5}$, followed by Korea and Israel. ${ }^{33}$ On the contrary, countries such as Australia, Norway and Finland had the lowest levels of exposure. In most OECD countries, exposure levels have decreased since the 1990s (except for Canada, New Zealand and Iceland - albeit from low levels), while in most BRIICS countries, exposure has gone up (except for Russia and Indonesia). The most marked reductions in exposure since the 1990s have occurred in Europe (e.g. Belgium, Italy, Poland, Netherlands, Czech Republic, Slovak Republic, Hungary, Germany, France, Austria and the UK) and to a lesser extent in Russia. The most dramatic rises have occurred in China and India, followed by Brazil. In China, as much as $78 \%$ of population is exposed to severe pollution by $\mathrm{PM}_{2.5}$ (above $35 \mu \mathrm{g} / \mathrm{m}^{3}$ ). In contrast, in Australia and Iceland, less than $1 \%$ of population is exposed to high levels of $\mathrm{PM}_{2.5}\left(\right.$ above $\left.10 \mu \mathrm{g} / \mathrm{m}^{3}\right){ }^{34}$

${ }^{33}$ Pollution of non-anthropogenic origin (airborne mineral dust, or 'desert dust') likely plays an important role in explaining the exposure levels in countries such as Saudi Arabia. However, as examined above, both anthropogenic and non- anthropogenic PM are relevant from the human health perspective.

${ }^{34}$ Results for 2012 and 2013 for some regions of Austria, Switzerland and Japan are overestimates, noticeably those in high-altitude areas. See Section 5 "Interpretation and Limitations" for more details. 
Figure 6. Population exposure to fine particles, TL1 country level (2013)

Mean exposure to $\mathrm{PM}_{2.5}$

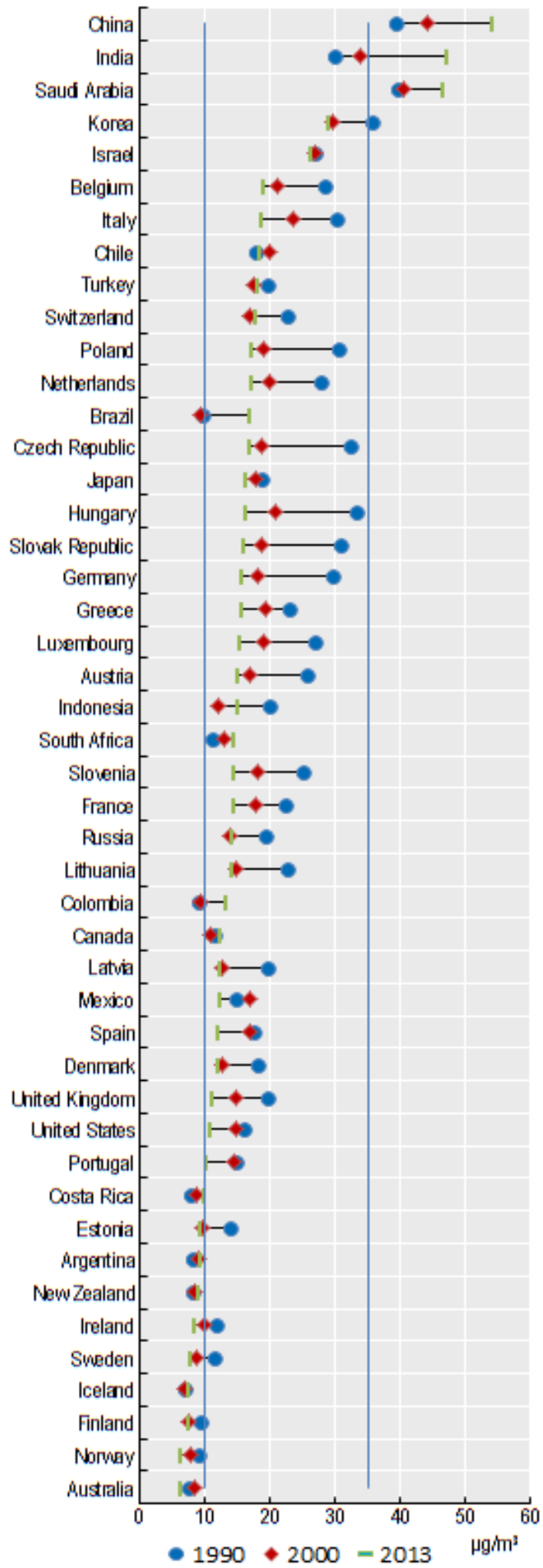

Percentage of population exposed to $\mathrm{PM}_{2.5}, 2013$

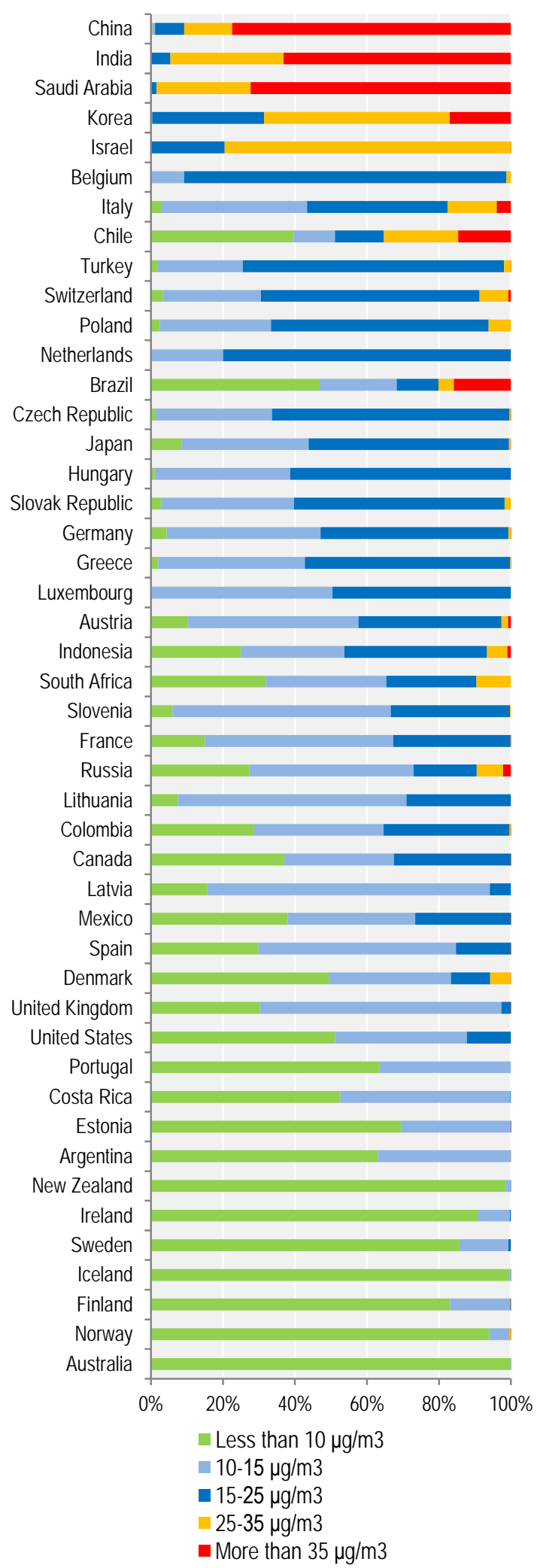




\subsection{Results at the regional level}

Results at the macro-regional level show an important variation of $\mathrm{PM}_{2.5}$ exposure levels within countries (Figure 7). ${ }^{35}$ Some countries with high country-level averages, such as China, India, Chile and Brazil, have regions where exposure is at relatively low levels. On the other hand, some countries at the bottom end of the chart with lower country-level exposure, such as Mexico and the United States, have regions with relatively high levels of exposure. ${ }^{36}$

Trends over time highlight improvements in exposure in most OECD, and deterioration in many fast-growing Asian countries (Figure 8). There is an important variation in exposure among regions in Europe, with the region of Lombardy (Milano) in northern Italy ranking the highest (Figure 9). Similarly in Asia, there are large differences among regions in China, India and Korea (Figure 10). Exposure in regions of Europe has improved significantly since the 1990s, particularly in parts of Central and Eastern Europe (Figure 11), and to a lesser extent in Asia in parts of Japan, Korea and western China (Figure 12).

Results at the micro-regional level can be generated in a similar fashion to permit an even greater granularity.

35 To delimit the macro regions, OECD's TL2 boundaries are used for most countries. When such information is not available, FAO's GAUL boundaries are used instead (for 7 of the 46 countries shown, including Argentina, Colombia, Costa Rica, Indonesia, Latvia, Lithuania and Saudi Arabia).

36 Results for 2012 and 2013 for some regions of Austria, Switzerland and Japan are overestimates, noticeably those in highaltitude areas. See Section 5 "Interpretation and Limitations" for more details.
Figure 7. Population exposure to fine particles, TL1 country level (2013)

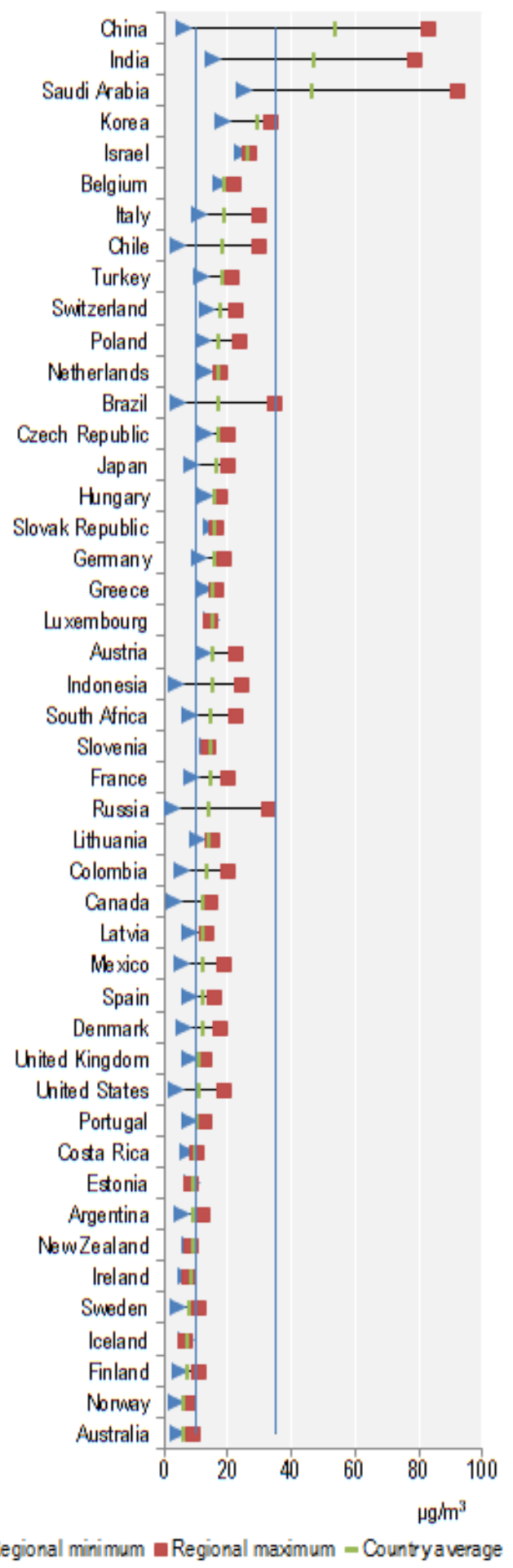


Figure 8. Mean exposure to $\mathrm{PM}_{2.5}$ in macro-regions (2013)

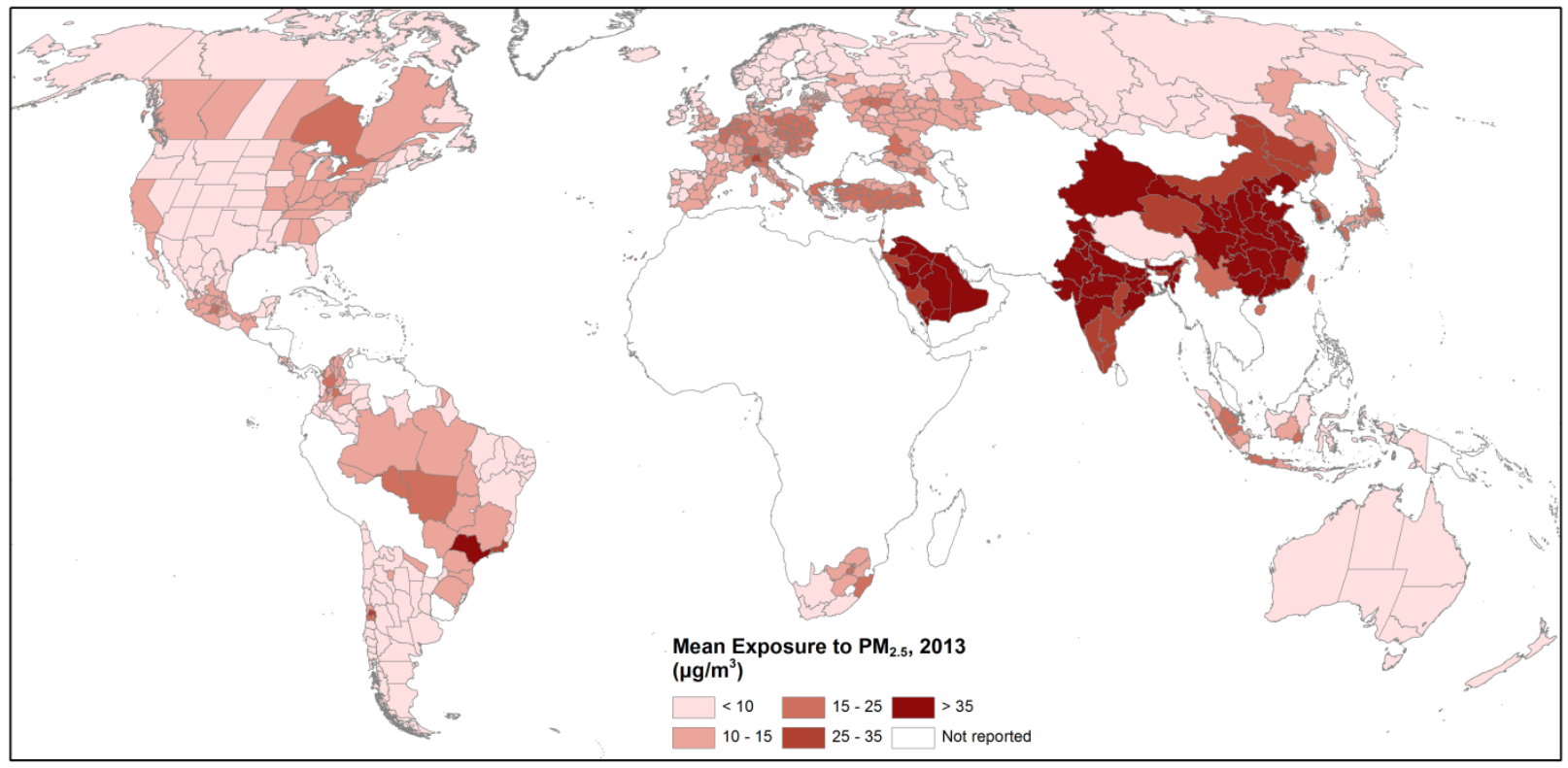

Figure 9. Mean exposure to $\mathrm{PM}_{2.5}$ in macro-regions (\% change 1990-2013)

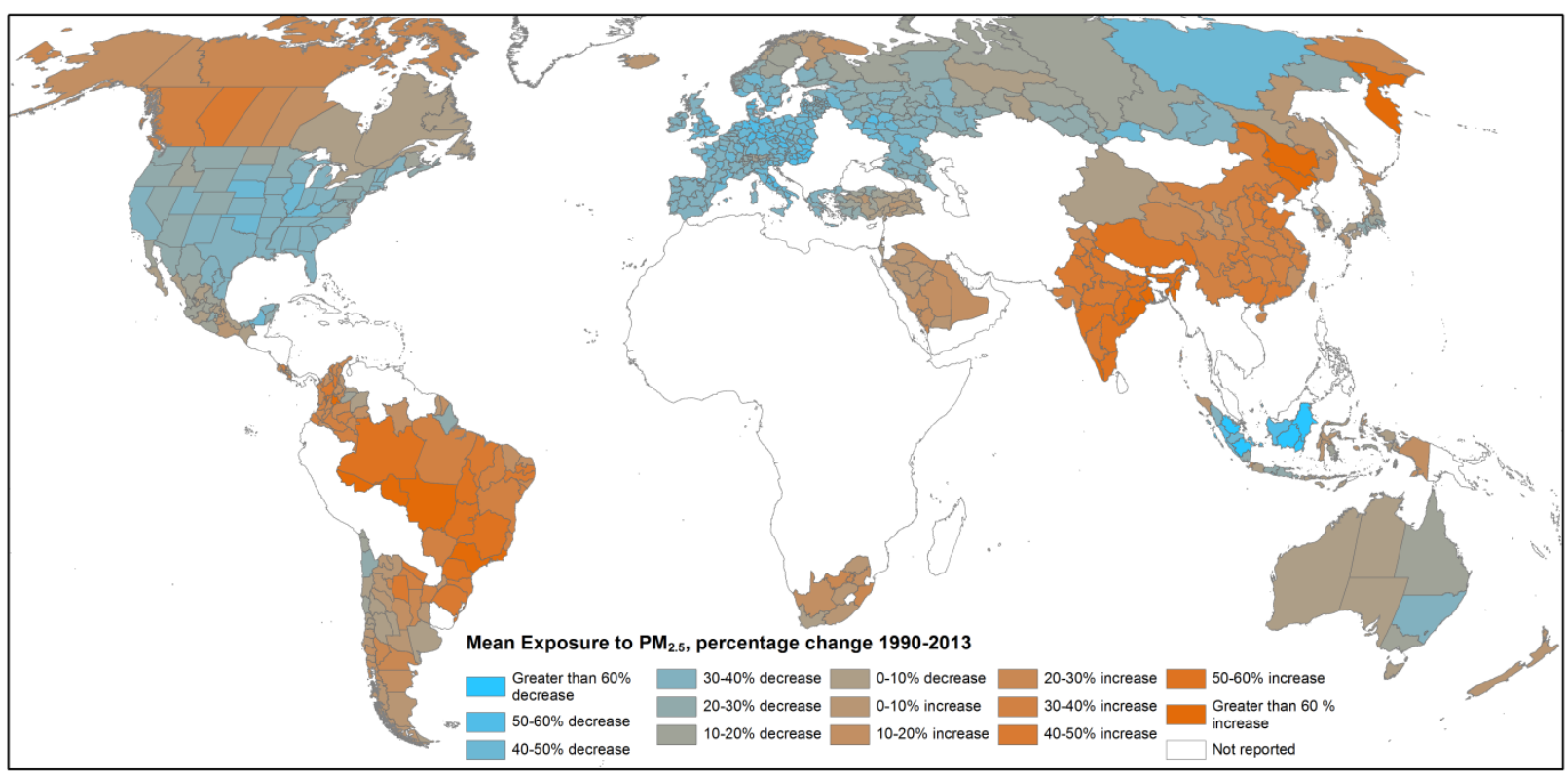


Figure 10. Mean exposure to $\mathrm{PM}_{2.5}$ in macro-regions in Europe (2013)

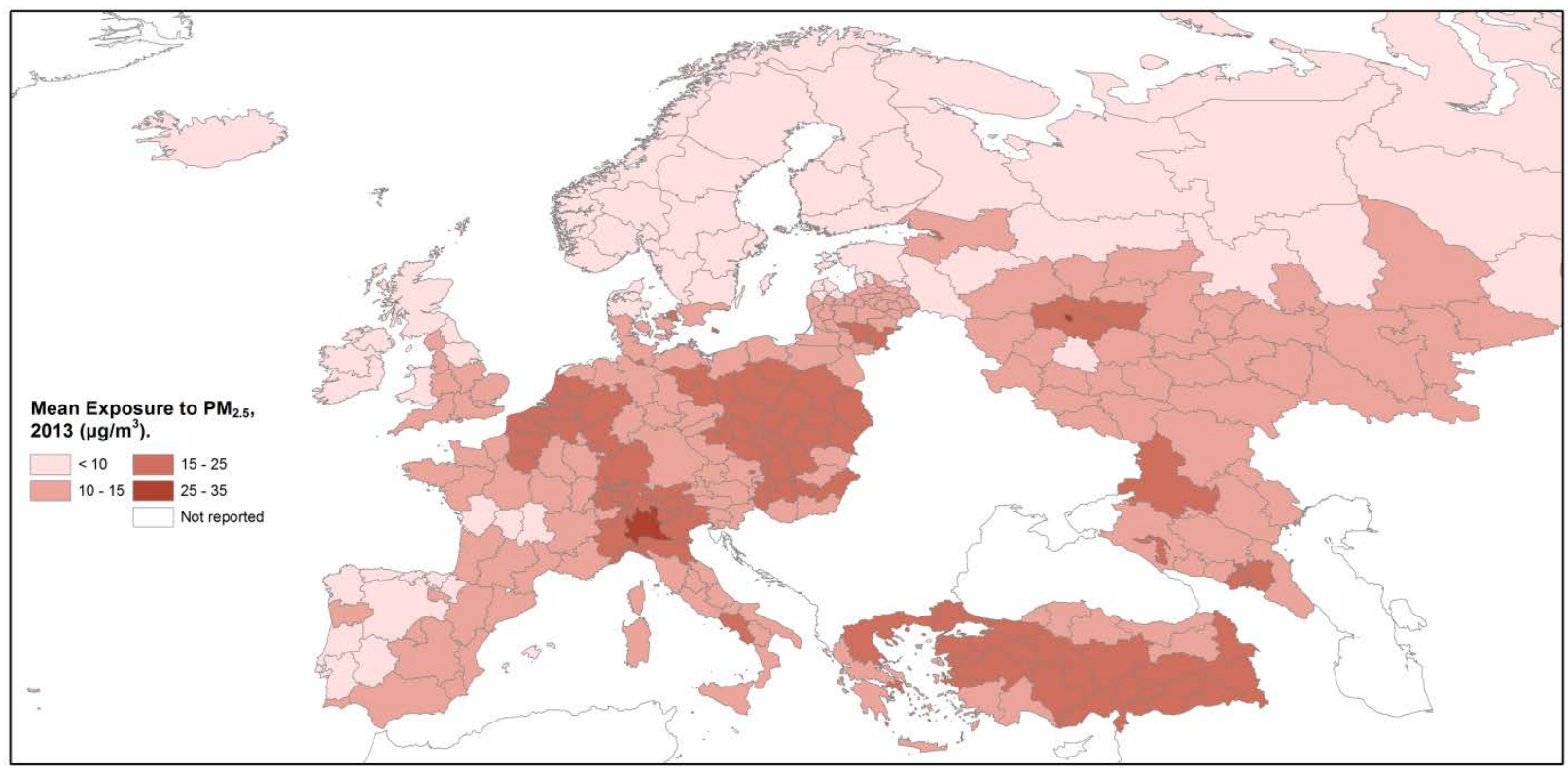

Figure 11. Mean exposure to $\mathrm{PM}_{2.5}$ in macro-regions in Asia (2013)

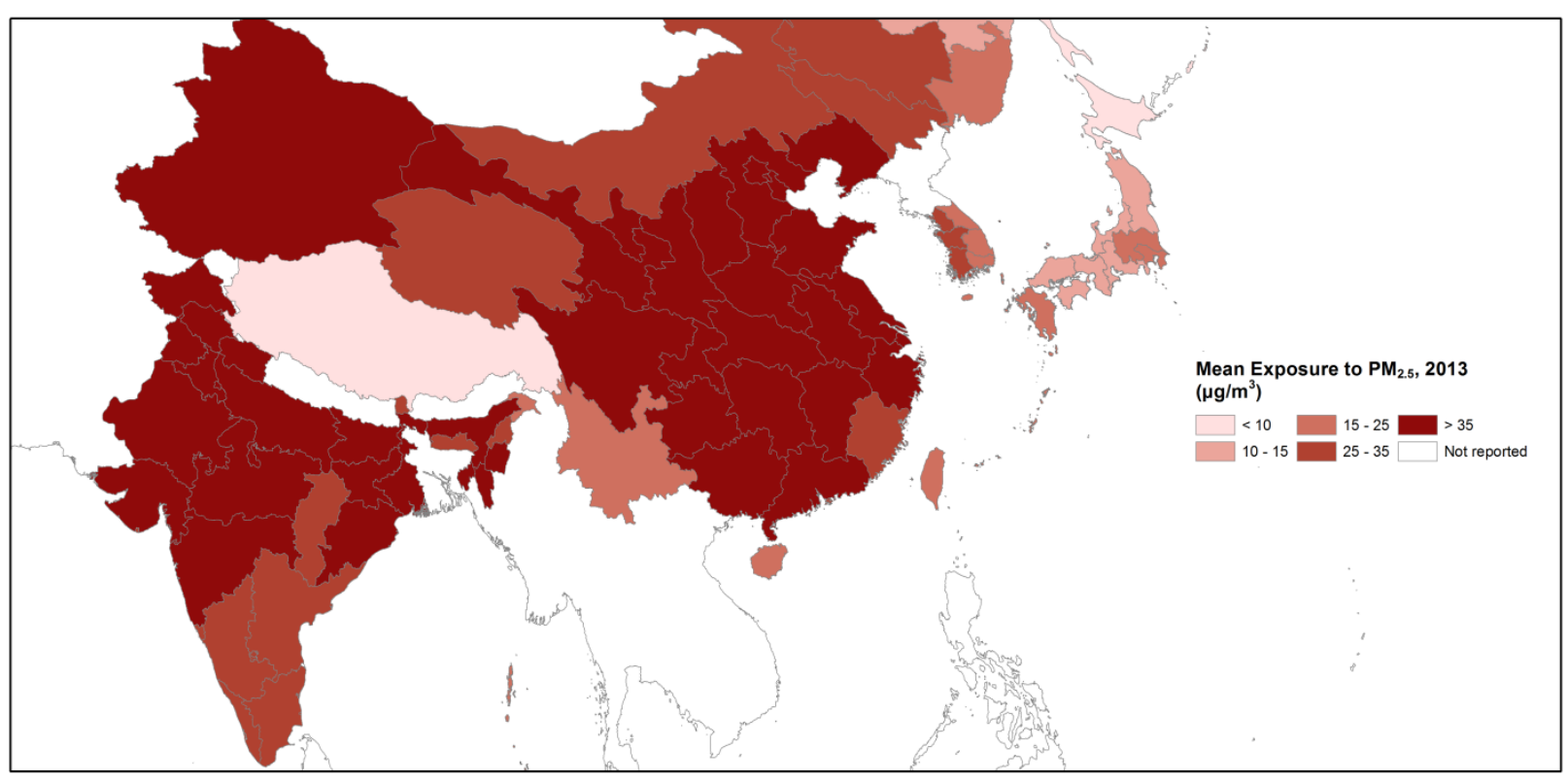


Figure 12. Mean exposure to $\mathrm{PM}_{2.5}$ in macro-regions in Europe (\% change 1990-2013)

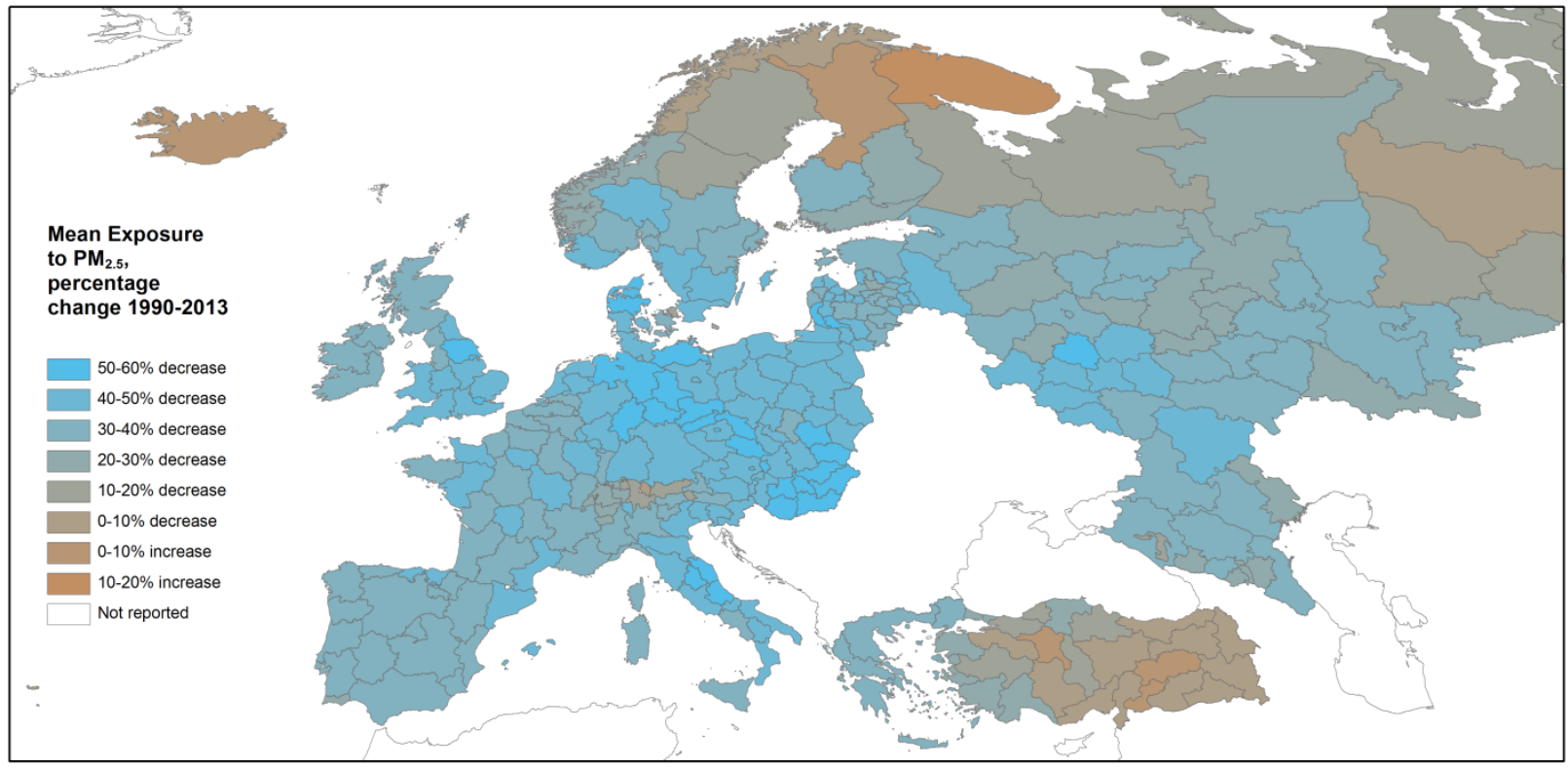

Figure 13. Mean exposure to $\mathrm{PM}_{2.5}$ in macro-regions in Asia (\% change 1990-2013)

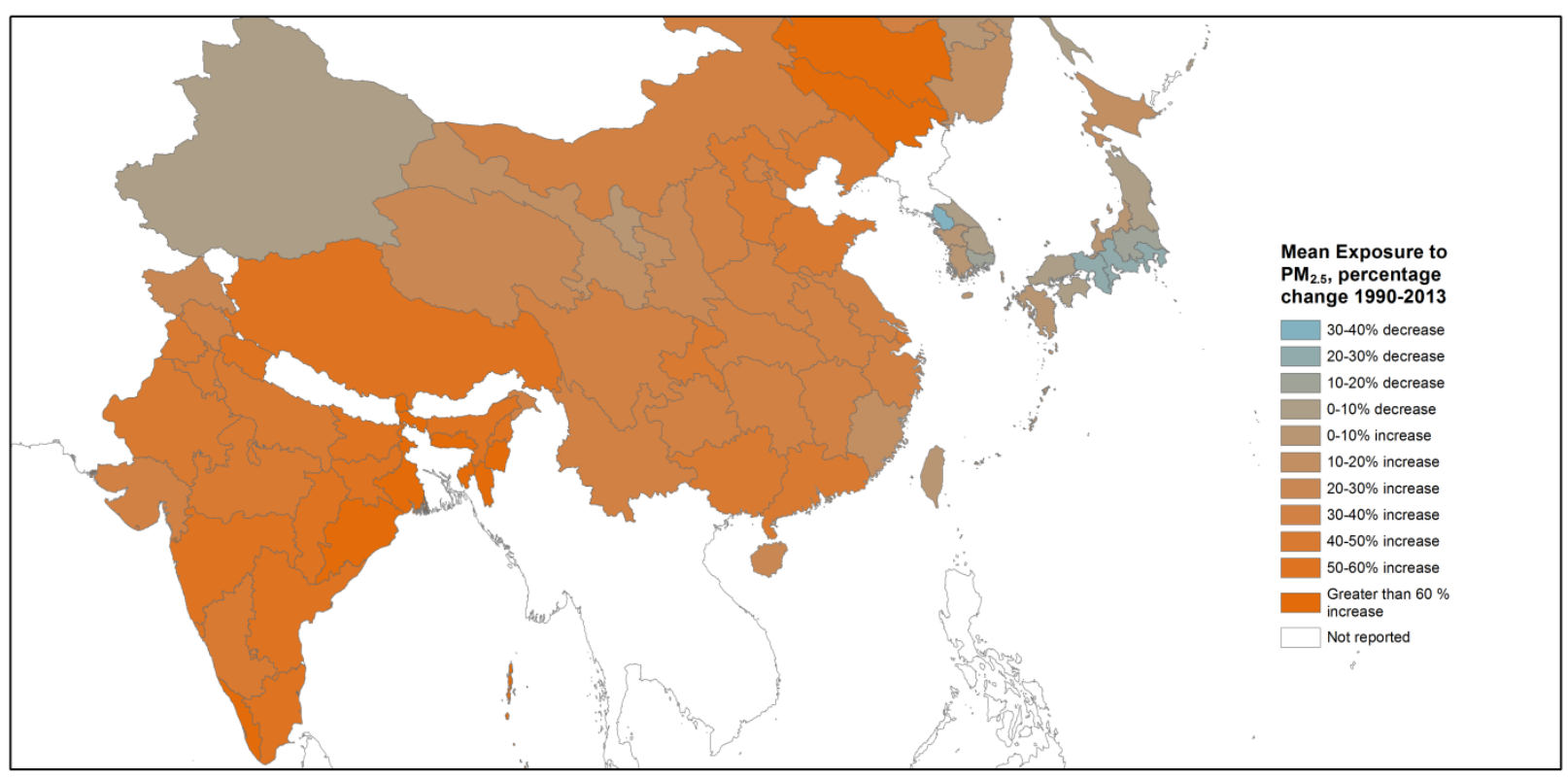




\subsection{Results at the metropolitan level}

Figure 13 shows the changing exposure in the metropolitan areas (FUA) of selected OECD capitals. $^{37}$ Overall, improvements in exposure have occurred essentially during the 1990s, with much smaller improvements throughout the 2000s. ${ }^{38}$

Important reductions in exposure with respect to the 1990 levels have been achieved in some metropolitan areas of Korea, Japan, Mexico and Chile (except e.g. for Santiago) (Figure 15). In Europe, metropolitan areas in parts of Germany have achieved significant reduction in exposure levels (Figure 17).
37 The OECD-EU definition of Functional Urban Areas (FUA) is currently applied only to 30 OECD countries.

38 When comparing exposure levels in FUAs over time one should keep in mind that the boundary of FUAs is by definition dynamic, reflecting evolution in urban patterns. However, the indicators shown here are all calculated with static FUA boundaries, using those that are currently available.
Figure 14. Mean exposure to PM2.5 in metropolitan areas (2013)

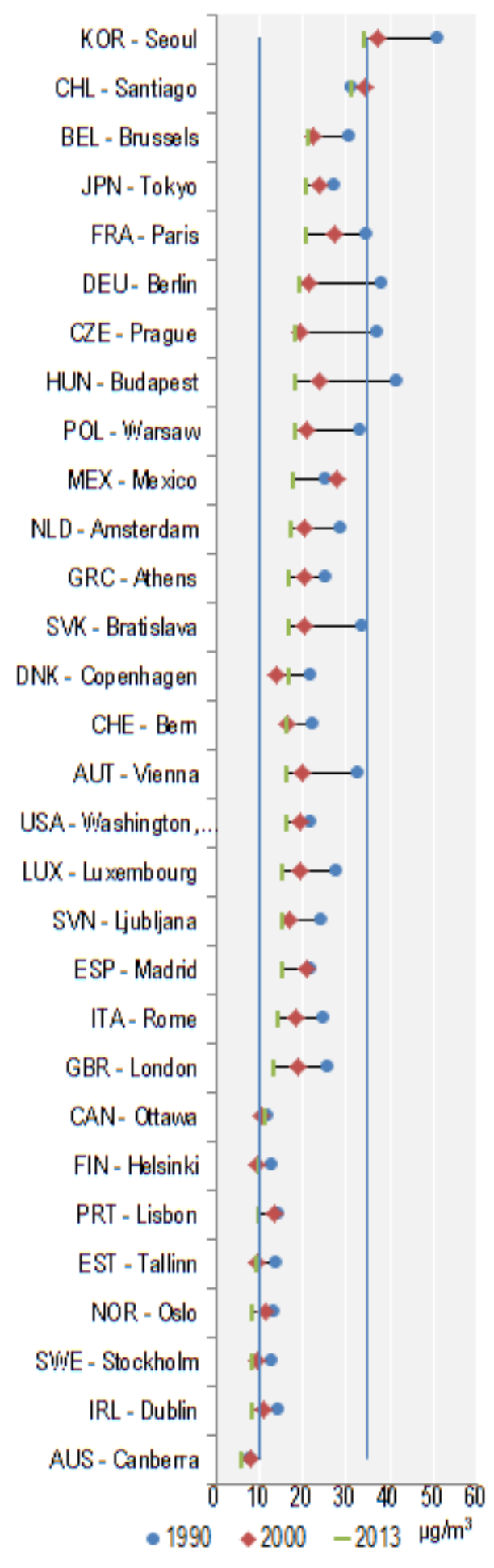


Figure 15. Mean exposure to $\mathrm{PM}_{2.5}$ in selected metropolitan areas of Asia and America (2013)

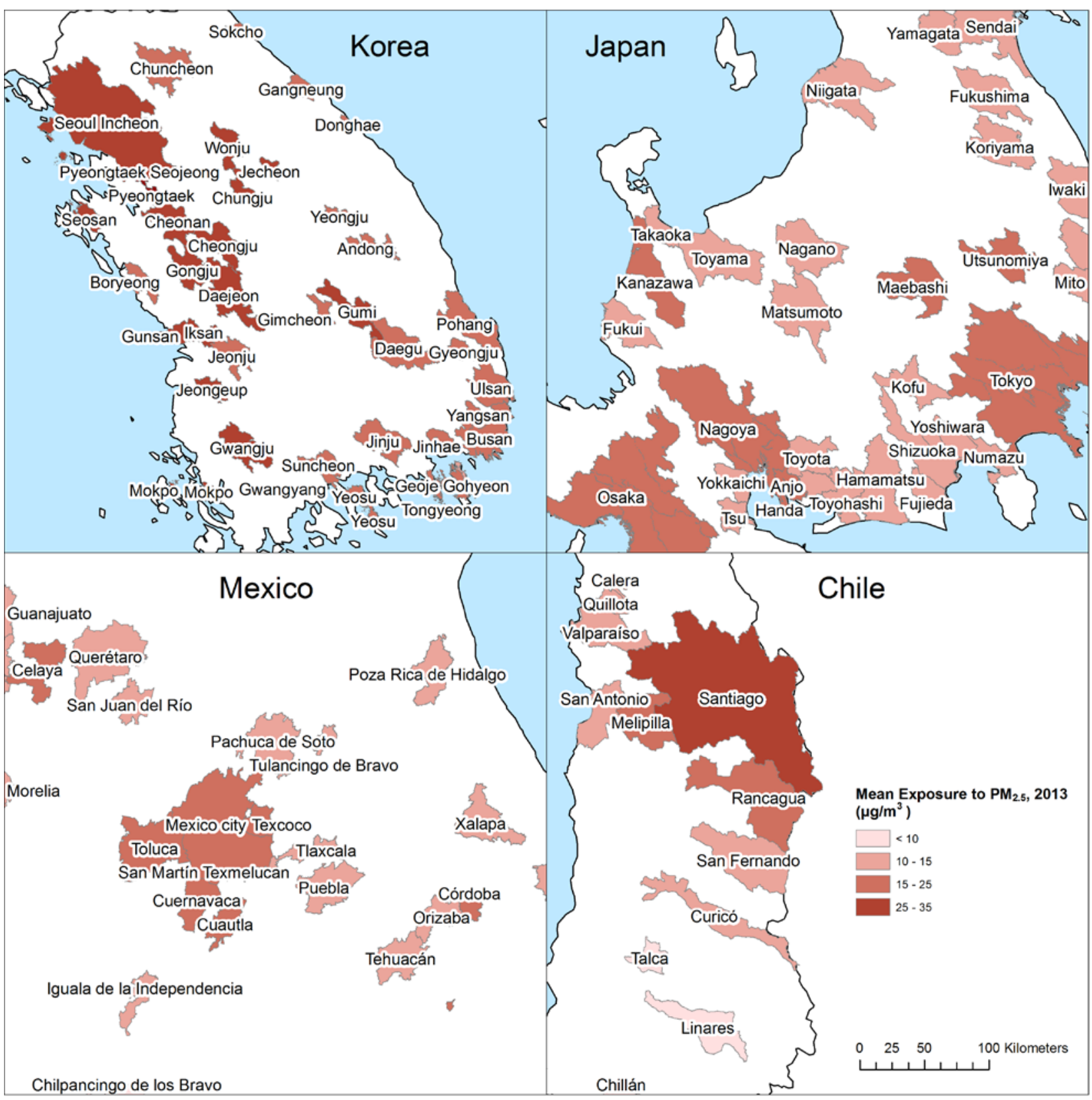


Figure 16. Mean exposure to $\mathrm{PM}_{2.5}$ in selected metropolitan areas of Asia and America (\% change 1990-2013)

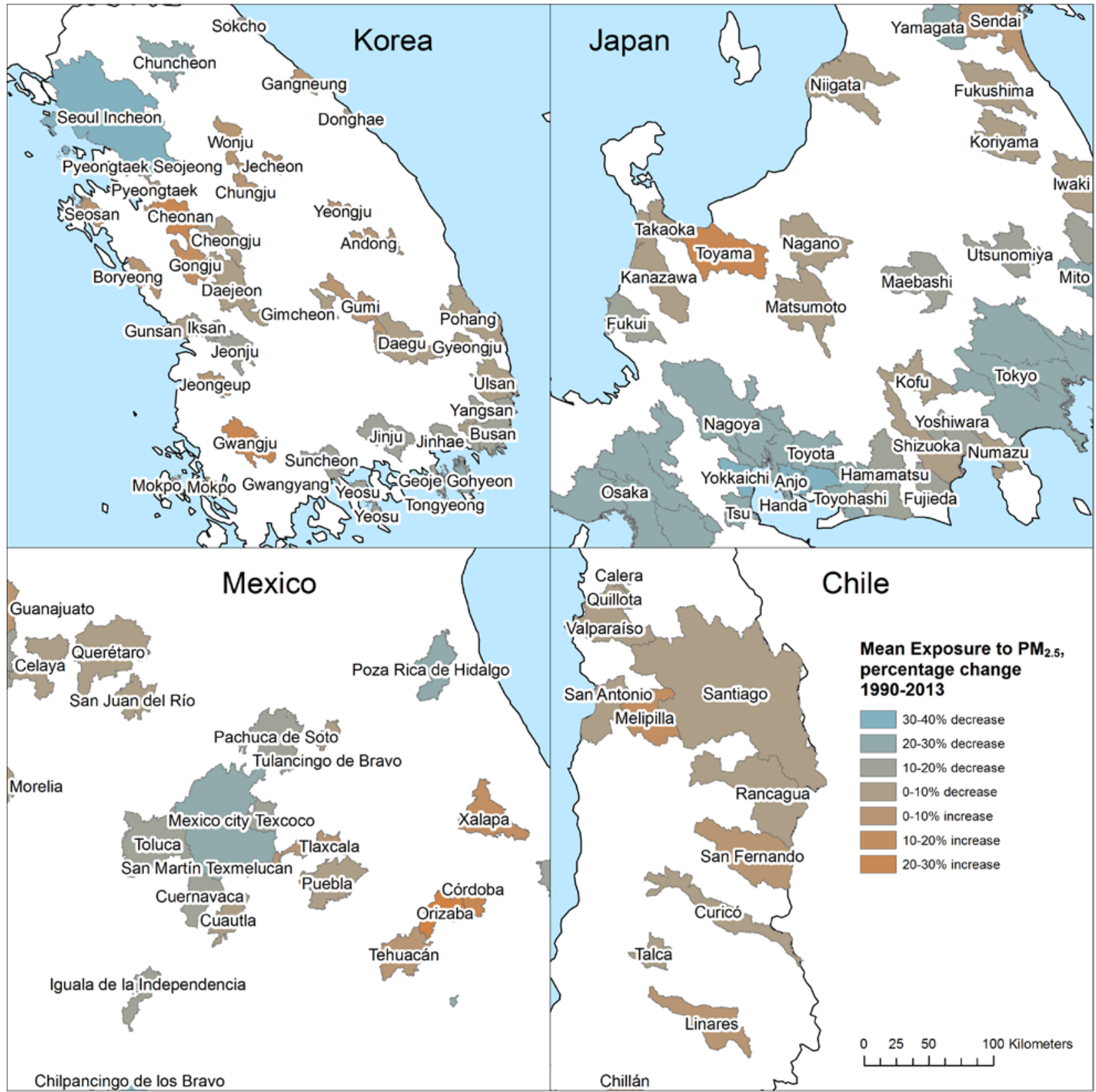


Figure 17. Mean exposure to $\mathrm{PM}_{2.5}$ in selected metropolitan areas in Europe (2013)

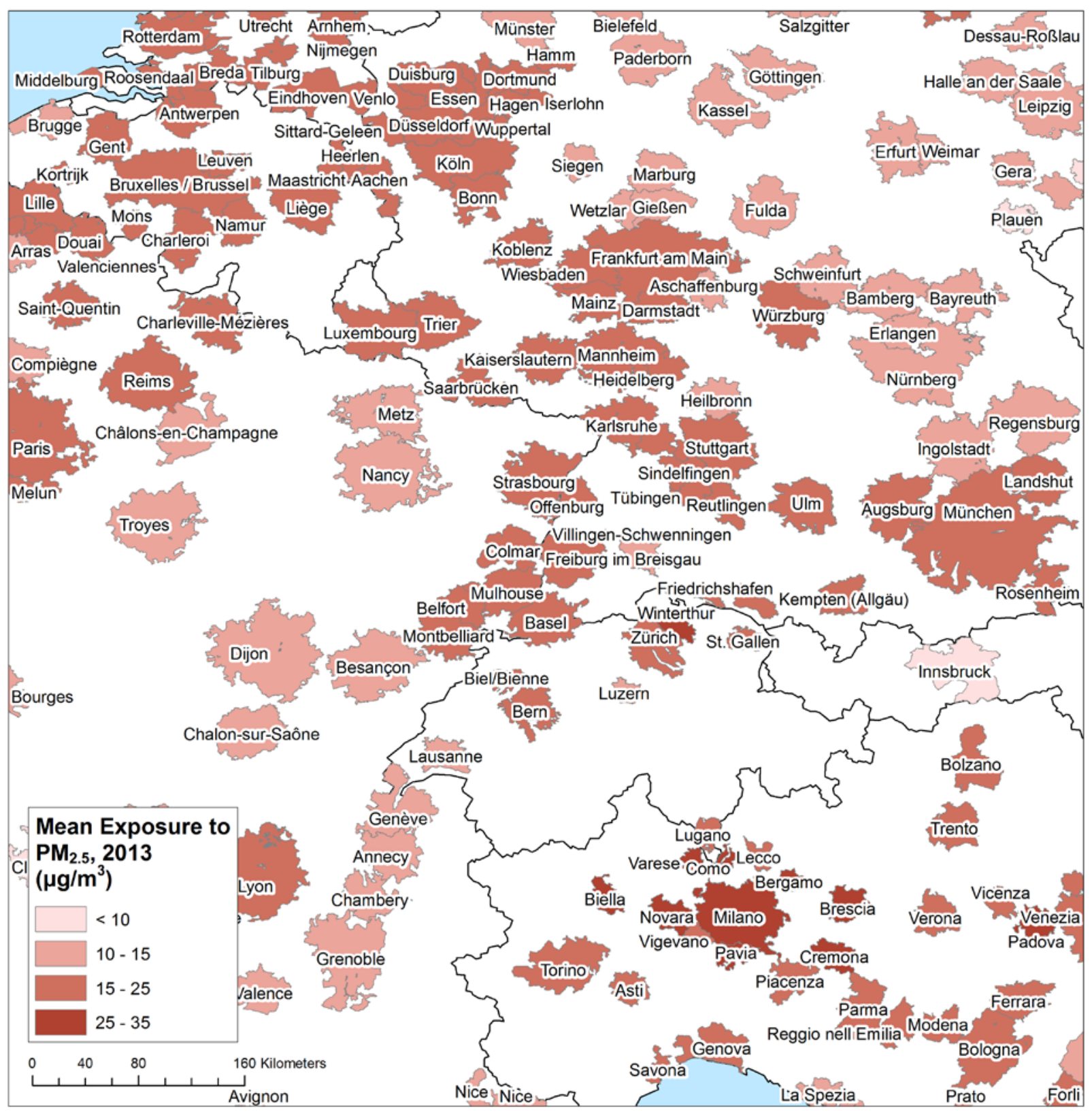


Figure 18. Mean exposure to $\mathrm{PM}_{2.5}$ in selected metropolitan areas in Europe (\% change 1990-2013)

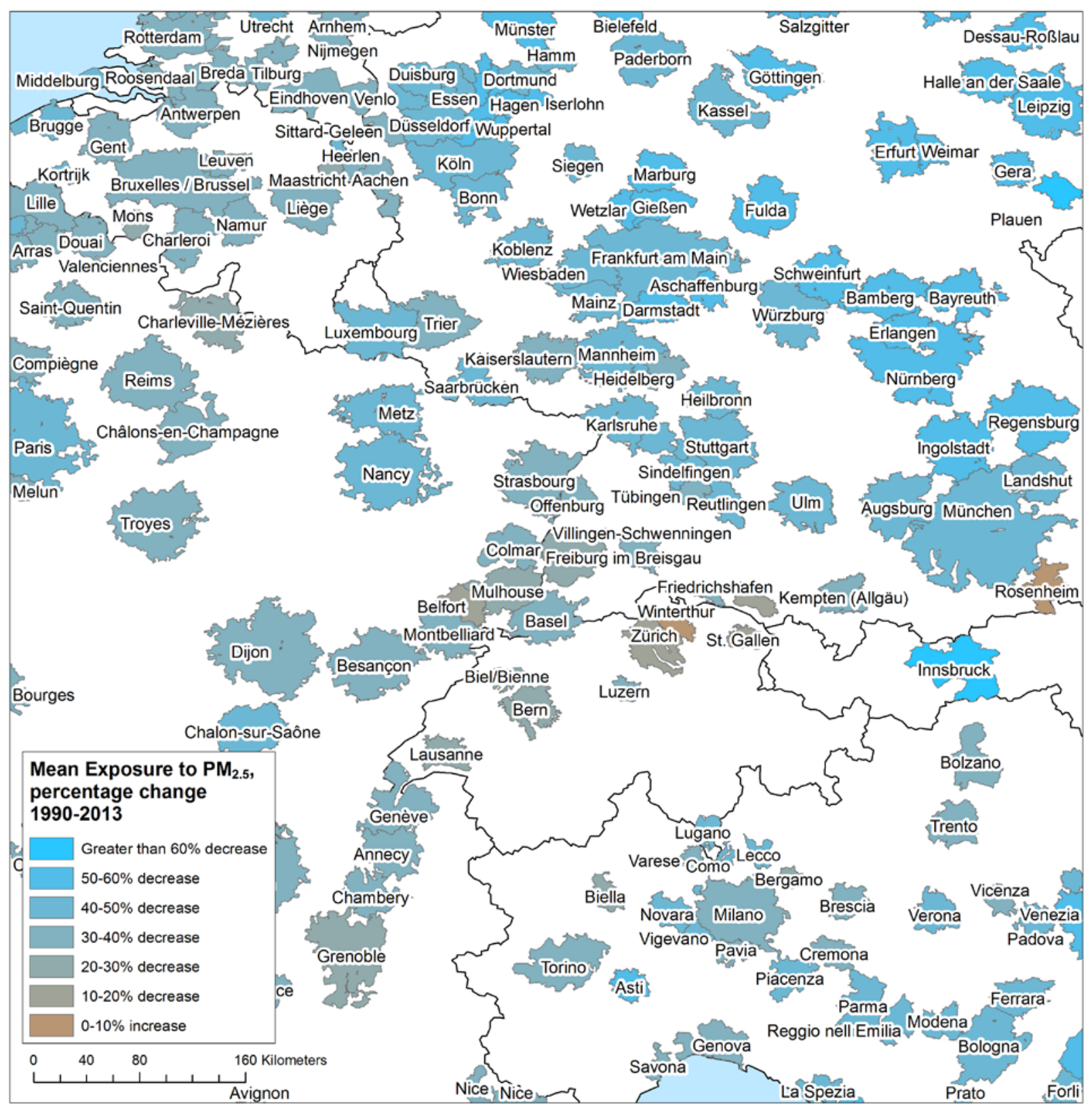




\section{INTERPRETATION AND LIMITATIONS}

The population exposure estimates presented here reflect pollution from combustion sources as well as airborne mineral dust, or desert dust. As of the forthcoming GBD 2015 update, the exposure indicators presented here will be accompanied with dust share indicating the percentage of $\mathrm{PM}_{2.5}$ that is not due to combustion. It must be emphasized, however, that there is no evidence suggesting differences in the human health impact of combustion versus dust particles.

The underlying estimates of $\mathrm{PM}_{2.5}$ concentrations, used for the present GBD 2013 assessment, are based on a global calibration function. This means that there is the potential to overestimate or underestimate concentrations in some locations. For some applications, population exposure estimates based directly on ground-based measurements may be more suitable than this hybrid approach (e.g. number of exceedances, daily or seasonal maxima, acute as opposed to chronic exposure), however, the true level of population exposure is unknown and mean annual estimates based primarily on data from ground-based measurements are not necessarily more accurate than those produced from the approach presented here. This is particularly relevant where national or regional estimates are based on a relatively low-density network of ground-based monitoring stations, stations that produce relatively few valid measurements, or where stations are not optimally located (see Turner, 2016). The most suitable estimates for a particular use should be determined on a case-by-case basis.

There is a data quality issue for years 2012 and 2013 that affects the complementary Percentage of population exposed to severe pollution by $P M_{2.5}$ indicators for some countries. This has led to overestimates for these years for countries including Austria, Switzerland, and Japan. For example the Austrian estimate for Percentage of population exposed to severe pollution by $P M_{2.5}$ for 2013 was $1.2 \%$, however in reality it is unlikely that any of the population was exposed to an annual average greater than $35 \mu \mathrm{g} / \mathrm{m}^{3}$ in that year. This overestimation is caused by a known issue with the GBD 2013 data for years 2012 and 2013 where estimates for 2013 were produced by applying the growth rate at each grid cell observed between 2010 and 2011 to an exponential growth function to estimate concentrations in 2013. In grid cells where there were large proportional increases between 2010 and 2011, this led to some outlier cells that far exceed the likely value. This noticeably affects some high-altitude areas.

This issue will be addressed in the following iterations of the GBD assessment and the indicators presented here will be updated accordingly. In the meantime, it is proposed that the complementary indicators (formulas [2] and [3]) are published with a caveat explaining that these are an overestimate for these countries. More generally, it is recommended that all results should be updated (and backdated where there have been methodological improvements applied to historical data) whenever the underlying $\mathrm{PM}_{2.5}$ concentration data are updated or improved, to ensure they remain the best informed and most up-to-date estimates.

There is also a potential to underestimate exposure in locations with high concentrations. In GBD 2013 this occurs notably for Chile, southern Poland and Turkey, and in specific urban areas with high levels of outdoor $\mathrm{PM}_{2.5}$ likely due to higher winter-time emissions when satellite retrievals are more limited due to more frequent winter cloud cover and night-time wood burning (Brauer et al. 2016).

A separate issue relates to the $0.1^{\circ}$ resolution of the concentration data. For some small cities surrounded by an area of relatively low concentrations, pixel averaging within each cell can lead to an underestimation in the $\mathrm{PM}_{2.5}$ exposure for the city. What should be regarded as 'too small' cannot be precisely defined however as a working guide, output areas that are less than 1.5 times the size of a cell in the input $\mathrm{PM}_{2.5}$ concentration data are flagged as possible underestimates in the output data. This possible underestimate flag is included in the results and applies to 102 out of 1197 (9.3\%) metropolitan areas (FUAs). 
For some regions, particularly snow-covered areas, small islands and coastal areas, there are no $\mathrm{PM}_{2.5}$ concentration estimates for part of the region because AOD measurements are not reliable in areas where the dominant land cover is very reflective. For these areas, concentration data are missing. In the interest of communicating the extent of coverage, the percentage of the population of a region for which there is $\mathrm{PM}_{2.5}$ concentration data is included with the results. This allows the extent to which measurements are representative of the population of the region to be understood.

The coverage at the country level is generally very good, approaching $95-100 \%$ of a country's population in most cases. The country with the lowest population coverage is Denmark at around 81\% coverage (a significant part of the population of Denmark lives along coastlines, islands and peninsular areas). At the macro-regional (TL2) level, coverage is generally over $90 \%$, however a small number of regions have gridded $\mathrm{PM}_{2.5}$ concentration data for only a small proportion of their total population. The Italian alpine region of Valle D'Aosta is problematic with data covering only around $6 \%$ of the population. The next most poorly represented region is Magallanes in Chile with population coverage around $33 \%$. At the metropolitan (FUA) level, the population coverage level is similar to that of TL2. Most FUAs have complete coverage, however 19 have less than 50\% coverage and Saint Denis on Réunion has no coverage because there is no data in the $\mathrm{PM}_{2.5}$ concentration dataset for the island. Figure 18 shows a box plot by quartile of population coverage at the TL1, TL2 and FUA levels, tails indicate maxima and minima and shows results for 46 TL1s, 547 TL2s and 1179 FUAs.

Figure 19. Population coverage of $\mathrm{PM}_{2.5}$ concentration data, 2013

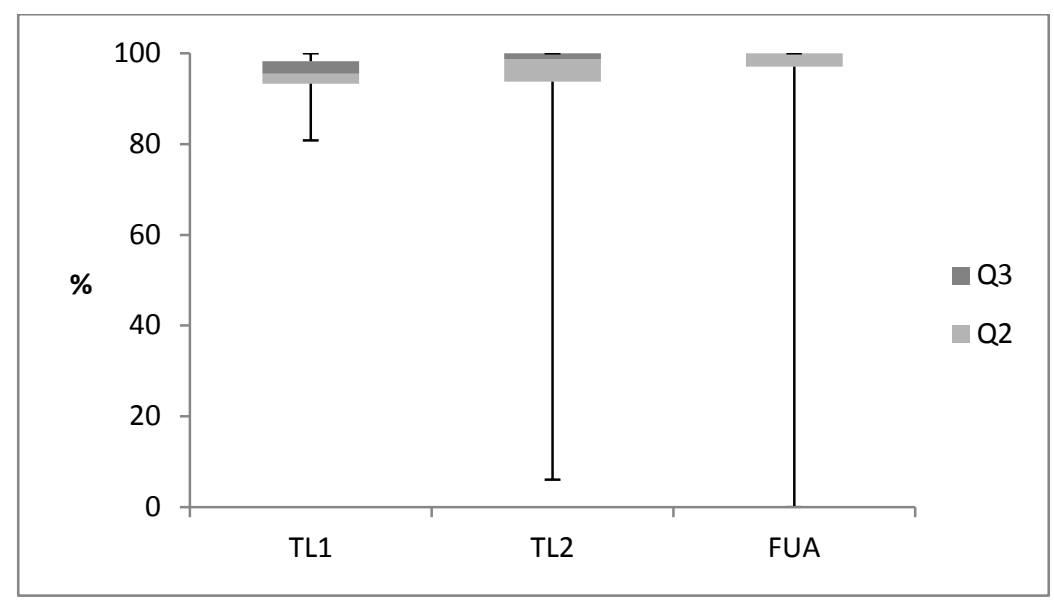

\section{CONCLUDING REMARKS AND NEXT STEPS}

The green growth indicators described in this paper build on previous OECD work, in particular the indicators of exposure to $\mathrm{PM}_{2.5}$ that were included in OECD (2011) and OECD (2015). The methodology is somewhat different as the green growth indicators are (i) based on a hybrid approach to estimating pollutant concentrations, involving a combination of satellite-based estimates and ground measurements; (ii) they are based on the most recent (up to 2013) estimates from research by the Global Burden of Disease (GBD) team, and (iii) they use a global population grid from SEDAC which, in the long run, is considered a better option than LandScan. 
The green growth indicators presented here supersede the one used in previous OECD work because the new estimates of underlying concentrations are more accurate (Brauer et al. 2016: page 84). This is due to methodological improvements in the chemical transport models and better calibration drawing on a much richer dataset of ground measurements. The new estimates are thus substantially betterinformed. The estimates are fully comparable across countries because the same methodology is applied including a global calibration function. Future refinements to the GBD methodology will be reflected in future updates of the indicators. The proposed methodology to calculate OECD indicators is thus fully aligned with that of the GBD, and estimates based on the hybrid approach have very recently been adopted also by the World Bank and used in the work of the US EPA and the WHO.

The green growth indicators presented here will be used in OECD country reviews (Environmental Performance Reviews and Economic Surveys) and its indicator reports (Environment at a Glance, Regions at a Glance). They could also be used in OECD horizontal work such as How's Life and the Better Life Index. There are many potential uses of this indicator in OECD's policy analysis work. For example, one application is to better understand the role of spatial planning and land use patterns on local air quality and population exposure. Another application would be to correlate exposure with wealth indicators, shedding more light on the linkages between environmental and social inequalities. Looking forward, there are links with the potential role of the OECD in the measurement of SDG indicators. In particular, the green growth headline indicator has been put forward to the UN Inter Agency Expert Group on the SDGs as one of the candidate indicators.

The methodology put forward in this paper will be extended to the regional and metropolitan levels of all countries for which such information is available. Moreover, these indicators will also be produced at the micro-regional level to complete the picture of the spatial distribution of populationweighted $\mathrm{PM}_{2.5}$ exposure.

It is expected that starting in 2016 (with the GBD 2015 assessment), the underlying PM $_{2.5}$ concentration data will be updated yearly which will enable these indicators to be kept up-to-date and timely, with a lag of approximately one year.

A methodology similar to the one presented here could be used to develop an indicator of population exposure to ozone and nitrogen dioxide, for example drawing on GBD's estimates of $\mathrm{O}_{3}$ and $\mathrm{NO}_{2}$ concentration fields. Moreover, GBD's human health impact estimates could be used to update and extend the information on economic costs of air pollution $\left(\mathrm{PM}_{2.5}\right.$ and $\left.\mathrm{O}_{3}\right)$ developed in OECD (2014). This is in line with the set of green growth indicators presented to the OECD Ministerial Council meeting in 2011 as part of the Green Growth Strategy, suggesting that the indicator is expected to reflect "environmentally-induced health problems and related costs" and "population exposure" is listed as a proxy. In follow-up, the proposal put forward in ENV/EPOC/WPEI(2012)2 envisaged that in the future the population exposure indicator "could be complemented with information on the economic effects of air pollution (e.g. loss of human capital and health care costs), as well as indicators of subjective well-being related to perceived air quality”.

Looking forward, a similar methodology drawing on geospatial data could be used to develop other environmental indicators and green growth indicators, such as exposure (of population, built property or ecosystems) to pollution, environmental risks and natural hazards, and calculation of related economic losses - another green growth indicator that is not yet measurable. 


\section{REFERENCES}

Brandt, N. (2014), “Greening the Property Tax”, OECD Working Papers on Fiscal Federalism, No. 17, OECD Publishing, Paris. http://dx.doi.org/10.1787/5jz5pzw9mwzn-en.

Brauer M., G. Freedman, J. Frostad, A. van Donkelaar, R.V. Martin, F. Dentener, R. van Dingenen, K. Estep, H. Amini, J.S. Apte, K. Balakrishnan, L. Barregard, D. Broday, V. Feigin, S. Ghosh, P.K. Hopke, L.D. Knibbs, Y. Kokubo, Y. Liu, S. Ma, L. Morawska, J.L. Texcalac Sangrador, G. Shaddick, H.R. Anderson, T. Vos, M.H. Forouzanfar, R.T. Burnett, and A. Cohen (2016), "Ambient Air Pollution Exposure Estimation for the Global Burden of Disease 2013", Environmental Science and Technology, Vol. 50, Issue 1, Pages 79-88.

Brauer, M. (2015), personal communication.

Brezzi, M. and D. Sanchez-Serra (2014), "Breathing the Same Air? Measuring Air Pollution in Cities and Regions”, OECD Regional Development Working Papers, 2014/11, OECD Publishing, Paris, http://dx.doi.org/10.1787/5jxrb7rkxf21-en.

Cárdenas Rodríguez, M., L. Dupont-Courtade and W. Oueslati (2015), “Air Pollution and Urban Structure Linkages: Evidence from European Cities”, OECD Environment Working Papers, No. 96, OECD Publishing, Paris, http://dx.doi.org/10.1787/5jrp6w9xlbq6-en.

Cropper, M. and S. Khanna (2014), “How should the World Bank estimate air pollution damages?”, Report RFF DP, pp. 14-30, Resources for the Future, Washington, DC.

Martin, R.V. (2008), Satellite remote sensing of surface air quality, Atmospheric Environment, Vol. 42, Issue 34, Pages 7823-7843.

OECD (2015), How's Life? 2015: Measuring Well-being, OECD Publishing, Paris, http://dx.doi.org/10.1787/how_life-2015-en.

OECD (2014), The Cost of Air Pollution: Health Impacts of Road Transport, OECD Publishing, Paris, http://dx.doi.org/10.1787/9789264210448-en.

OECD (2013), Regions at a Glance 2013, OECD Publishing, Paris, http://dx.doi.org//10.1787/reg_glance-2013-en.

OECD (2012), Redefining "Urban": A New Way to Measure Metropolitan Areas, OECD Publishing, Paris, http://dx.doi.org/10.1787/9789264174108-en.

OECD (2011), Regions at a Glance 2011, OECD Publishing, Paris, http://dx.doi.org/10.1787/reg_glance-2011-en.

SEDAC (2015), Gridded Population of the World, (GPW), v4. NASA Socioeconomic Data and Applications Center (SEDAC).

Turner, J. (2016), “Air pollution exposure indicators: review of ground-level monitoring data availability and proposed calculation method”, OECD Green Growth Papers, No. 2016/01, OECD Publishing, Paris.

van Donkelaar A, R.V. Martin, M. Brauer, B.L. Boys (2015), "Use of satellite observations for long-term exposure assessment of global concentrations of fine particulate matter," Environmental Health Perspectives 123:135-143.

van Donkelaar, A., R.V. Martin, M. Brauer, R. Kahn, R. Levy, C. Verduzco and P.J. Villeneuve (2010), "Global estimates of exposure to fine particulate matter concentrations from satellite-based aerosol optical depth”, Environmental Health Perspectives 118(6), 847-855.

WHO (2006), WHO Air quality guidelines for particulate matter, ozone, nitrogen dioxide and sulfur dioxide - Global update 2005 - Summary of risk assessment, World Health Organisation. 
www.oecd.org/greengrowth 